\title{
The Navier-Stokes Equations on a Bounded Domain $\star$
}

\section{Vladimir Scheffer}

Department of Mathematics, Rutgers University, New Brunswick, NJ 08903, USA

\begin{abstract}
Suppose $U$ is an open bounded subset of 3-space such that the boundary of $U$ has Lebesgue measure zero. Then for any initial condition with finite kinetic energy we can find a global (i.e. for all time) weak solution $u$ to the time dependent Navier-Stokes equations of incompressible fluid flow in $U$ such that the curl of $u$ is continuous outside a locally closed set whose $5 / 3$ dimensional Hausdorff measure is finite.
\end{abstract}

\section{Introduction}

Definition 1.1. Suppose $f$ is a $C^{\infty}$ function defined on an open subset $V$ of $R^{3} \times R$. If $i \in\{1,2,3\}$ then $D_{i} f$ is the partial derivative of $f$ with respect to the $i$ component of $R^{3}$. The partial derivative of $f$ with respect to the $R$ component of $R^{3} \times R$ is denoted by $D_{t} f$. The letter $t$ is used because the second component of $R^{3} \times R$ represents time. The vector function $\left(D_{1} f, D_{2} f, D_{3} f\right)$ is written $D f$. The function $\Delta f$ is defined on the set $V$ by $(\Delta f)(x, t)=\sum_{i=1}^{3} D_{i}\left(D_{i} f\right)(x, t)$. When the range of $f$ is $R^{3}$ we define the functions $\operatorname{div}(f): V \rightarrow R$ and $\operatorname{curl}(f): V \rightarrow R^{3}$ by

$$
(\operatorname{div}(f))(x, t)=\sum_{i=1}^{3} D_{i} f_{i}(x, t)
$$

and

$$
(\operatorname{curl}(f))(x, t)=\left(\left(D_{2} f_{3}-D_{3} f_{2}\right)(x, t),\left(D_{3} f_{1}-D_{1} f_{3}\right)(x, t),\left(D_{1} f_{2}-D_{2} f_{1}\right)(x, t)\right) .
$$

We extend these definitions in the obvious way to the case where $f$ is a distribution. Hausdorff measure is defined in Definition $6.5, R^{+}$is the set $\{t \in R: t>0\}, L^{p}$ is the Lebesgue space of $p$-integrable functions with norm \|\|$_{p}$, and the summation convention for repeated indices is used. If $A$ and $B$ are sets then $A \sim B=\{x \in A: x \notin B\}$.

$\star \quad$ This research was supported in part by the National Science Foundation Grant MCS-7903361 
The purpose of this paper is to prove the following:

Theorem 1.2. Suppose $U$ is an open bounded subset of $R^{3}$ such that the boundary of $U$ has Lebesgue measure zero. Suppose that $w^{0}: R^{3} \rightarrow R^{3}$ is an $L^{2}$ function such that $w^{0}(x)=0$ for almost every $x \notin U$ and $\int w_{i}^{0}(x) D_{i} f(x) d x=0$ for every $C^{\infty}$ function $f: R^{3} \rightarrow R$ with compact support. Then there exists a set $S \subset U \times R^{+}$and there exists an $L^{10 / 3}$ function $u: R^{3} \times R^{+} \rightarrow R^{3}$ such that $D u$ is an $L^{2}$ function and the following properties hold:

(1) $u(x, t)=0$ for almost every $(x, t) \notin U \times R^{+}$,

(2) $\int_{0}^{\infty} \int_{R^{3}} u_{i}(x, t) D_{i} f(x, t) d x d t=0$ if $f: R^{3} \times R \rightarrow R$ is a $C^{\infty}$ function with compact support,

(3) $-\int_{R^{3}} w_{i}^{0}(x) f_{i}(x, 0) d x=\int_{0}^{\infty} \int_{R^{3}}\left[u_{i}(x, t)\right]\left[D_{t} f_{i}(x, t)+\Delta f_{i}(x, t)\right] d x d t$

$$
+\int_{0}^{\infty} \int_{R^{3}} u_{j}(x, t) u_{i}(x, t) D_{j} f_{i}(x, t) d x d t
$$

if $f: R^{3} \times R \rightarrow R^{3}$ is a $C^{\infty}$ function with compact support such that $\operatorname{div}(f)=0$ and the support of $f$ is contained in $U \times R$,

(4) if $K$ is a compact subset of $U \times R^{+}$then $K \cap S$ is compact,

(5) the function curl $(u)$ can be modified on a set of Lebesgue measure zero so that it becomes continuous on $\left(U \times R^{+}\right) \sim S$,

(6) the 5/3 dimensional Hausdorff measure of $S$ is finite,

(7) the one dimensional Hausdorff measure of $S \cap\left(R^{3} \times\{t\}\right)$ is a bounded function of $t \in R^{+}$.

A few informal comments will clarify the statement of this theorem. The two factor spaces in $R^{3} \times R^{+}$represent space and time, respectively. The function $w^{0}$ is a given velocity vector field with finite kinetic energy which represents an incompressible flow inside $U$. This function should be thought of as being defined on $U$. Making $w^{0}$ equal to zero outside of $U$ helps to simplify the exposition. Parts (1)-(3) state that $u$ is a time dependent weak solution to the Navier-Stoke equations of incompressible fluid flow in $U$ with initial condition $w^{0}$. Again, we make $u$ equal to zero outside of $U \times R^{+}$to simplify certain statements. Part (1) and $D u \in L^{2}$ are a weak way of saying that $u$ is zero on the boundary of $U$. The function $\operatorname{curl}(u)$ is an element of $L^{2}$ (since $D u \in L^{2}$ ). Hence curl $(u)$ is an equivalence class of functions which differ only on sets of Lebesgue measure zero. Parts (4), (5) state that one of the functions in this equivalence class is continuous on the open set $\left(U \times R^{+}\right) \sim S$. Parts (6), (7) say that $S$ is a very small set.

Definition 1.3. If $-\infty \leqq a<b \leqq \infty$ then

$$
\begin{array}{ll}
(a, b)=\{x: a<x<b\}, & {[a, b]=\{x: a \leqq x \leqq b\},} \\
{[a, b)=\{x: a \leqq x<b\},} & \text { and } \quad(a, b]=\{x: a<x \leqq b\} .
\end{array}
$$

Euclidean norms will be denoted by | I. If $f$ is a function defined on a subset of $R^{3}$ and $i \in\{1,2,3\}$ then $D_{i} f$ is the partial derivative of $f$ with respect to the $i$ component of $R^{3}$ and $D f=\left(D_{1} f, D_{2} f, D_{3} f\right)$. If $i, j, k \in\{1,2,3\}$ then $D_{i j} f=D_{i}\left(D_{j} f\right)$ 
and $D_{i j k} f=D_{i}\left(D_{j}\left(D_{k} f\right)\right)$. The collection of $C^{\infty}$ functions with compact support from $X$ into $Y$ will be written $C_{0}^{\infty}(X, Y)$. An absolute constant is a positive constant that does not depend on any of the parameters in this paper. Since there are several hundred absolute constants in this paper, we will denote them by the letter $C$ without bothering to distinguish most of them with subscripts. Thus the various $C$ 's below represent different constants. If a constant depends only on a parameter $H$ we write it as $C(H)$.

This research was inspired by the work of Almgren [1], Leray [3], and Mandelbrot [4]. There are other results of this nature in [5,6] and [7], where it was assumed that $U$ is all of euclidean space. In [5] it was shown that $u$ is continuous except for a locally closed subset of $R^{3} \times R^{+}$whose Hausdorff dimension is at most 2. In [6] we had a similar result for flows in 5 dimensional space-time (with $R^{3} \times R^{+}$replaced by $R^{4} \times R^{+}$) where the Hausdorff dimension of the singular set was shown to be at most 3 . The proofs in [5] and [6] are very different from the proof in this paper, which is based on the method of [7]. Paper [7] was a primitive version of this type of result in which the conclusion resembled statement (7) of Theorem 1.2.

\section{Technical Preparation}

Throughout this section we assume that we are given a continuous function $u: R^{3} \times R^{+} \rightarrow R^{3}$ such that

$$
\left\{\int_{R^{3}}|u(x, t)|^{2} d x: t>0\right\}
$$

is a bounded set of real numbers,

$D u$ is an $L^{2}$ function.

We also assume that $\{a, c\} \subset R^{3},\{b, d\} \subset R,\{m, p, n, q\}$ is a set of integers, and the following six properties hold:

$$
\begin{aligned}
& b>2^{-2 m}, \\
& |a-c|<2^{-m}, \\
& b-2^{-2 m}<d \leqq b, \\
& 2^{-(n+1)}<2^{-m}-|a-c| \leqq 2^{-n}, \\
& 2^{-2(p+1)}<d-\left(b-2^{-2 m}\right) \leqq 2^{-2 p}, \\
& q=\text { maximum of } n \text { and } p .
\end{aligned}
$$

Frequent use will be made of the following definition:

Definition 2.1. If $A \subset R^{3} \times R$ and $f$ is a function defined on $A$ we use the abbreviations $I(f, A)=\int_{A} f$ and $M(f, A)=$ the supremum of $\{|\mathrm{f}(\mathrm{x}, \mathrm{t})|:(\mathrm{x}, \mathrm{t}) \in \mathrm{A}\}$. If 
$x \in R^{3}, t \in R, r>0, s>0$, and $h>0$ then

$$
\begin{aligned}
B(x, r) & =\left\{y \in R^{3}:|y-x| \leqq r\right\}, \\
K(x, t, r, s) & =\left\{(y, w) \in R^{3} \times R:|y-x| \leqq r \text { and } t-s \leqq w \leqq t\right\}, \\
A(x, r, h) & =\left\{y \in R^{3}: r-h \leqq|y-x| \leqq r+h\right\}, \\
T(x, t, r, s, h) & =\left\{(y, w) \in R^{3} \times R: r-h \leqq|y-x| \leqq r+h \text { and } t-s \leqq w \leqq t\right\}, \\
D(t) & =\left\{(y, w) \in R^{3} \times R: w \leqq t\right\} .
\end{aligned}
$$

Lemma 2.2. If $B(y, r / 4) \subset B(x, r)$ and $t>s>0$ then

$$
\begin{aligned}
& I\left(|u|^{2}, K(x, t, r, s)\right) \\
& \quad \leqq C r^{3} s\left(M\left(|u|^{2}, K(y, t, r / 4, s)\right)\right)+C r^{2}\left(I\left(|D u|^{2}, K(x, t, r, s)\right)\right) .
\end{aligned}
$$

Proof. Using the continuity of $u$, the assumption $D u \in L^{2}$, approximation by smooth functions, and Lemma 1.2 of [7] we obtain

$$
\begin{aligned}
\int_{B(x, r)}|u(z, w)|^{2} d z \leqq & \left.C r^{3} \text { (supremum }\left\{|u(z, w)|^{2}: z \in B(y, r / 4)\right\}\right) \\
& +C r^{2}\left(\int_{B(x, r)}|D u(z, w)|^{2} d z\right)
\end{aligned}
$$

for almost every $w>0$. Now integrate over $t-s \leqq w \leqq t$.

Lemma 2.3. We have $n \geqq m$ and $p \geqq m$.

Proof. From (2.6) we obtain $2^{-(n+1)}<2^{-m}-|a-c| \leqq 2^{-m}$. Since $n$ and $m$ are integers, we conclude $n \geqq m$. From (2.7) and (2.5) we obtain

$$
2^{-2(p+1)}<d-\left(b-2^{-2 m}\right) \leqq b-\left(b-2^{-2 m}\right)=2^{-2 m} .
$$

Again, the fact that $p$ and $m$ are integers implies $p \geqq m$.

We will use the abbreviation

$$
G(i)=K\left(a, b, 2^{-m}-2^{-i}, 2^{-2 m}-2^{-2 i}\right) \quad \text { if } \quad i>m .
$$

Lemma 2.4. If $k$ is an integer, $k \geqq m+1$, and $2^{-(m+1)}<|a-c|$ then

(a) if $k \leqq n+1$ and $k \leqq p+1$ then

$$
\begin{aligned}
2^{4 k} I\left(|u|^{2}, K\left(c, d, 2^{-k}, 2^{-2(p+2)}\right)\right) \leqq & C 2^{k} 2^{-2 p} M\left(|u|^{2}, D(d) \cap G(p+2)\right) \\
& +C 2^{2 k} I\left(|D u|^{2}, T\left(a, b, 2^{-m}, 2^{-2 m}, 2^{-k+2}\right)\right),
\end{aligned}
$$

(b) if $n>p, p+2 \leqq k$, and $k \leqq n+1$ then

$$
\begin{aligned}
2^{4 k} I\left(|u|^{2}, K\left(c, d, 2^{-k}, 2^{-2 k}\right)\right) \leqq & C 2^{-k} M\left(|u|^{2}, D(d) \cap G(k+1)\right) \\
& +C 2^{2 k} I\left(|D u|^{2}, T\left(a, b, 2^{-m}, 2^{-2 m}, 2^{-k+2}\right)\right),
\end{aligned}
$$

(c) if $n \leqq p, n+2 \leqq k$, and $k \leqq p+1$ then

$$
2^{4 k} I\left(|u|^{2}, K\left(c, d, 2^{-k}, 2^{-2(p+2)}\right)\right) \leqq C 2^{k} 2^{-2 p} M\left(|u|^{2}, D(d) \cap G(p+2)\right),
$$

(d) if $k \geqq n+2$ and $k \geqq p+2$ then

$$
2^{4 k} I\left(|u|^{2}, K\left(c, d, 2^{-k}, 2^{-2 k}\right)\right) \leqq C 2^{-k} M\left(|u|^{2}, D(d) \cap G(q+2)\right) .
$$


Proof. From the hypotheses we obtain $|a-c|>2^{-(m+1)} \geqq 2^{-k}$.

This allows us to make the following definition: $e_{k}$ is the point on the line segment joining $a$ and $c$ that satisfies $\left|e_{k}-c\right|=(3 / 4) 2^{-k}$.

We have

$$
B\left(e_{k},(1 / 4) 2^{-k}\right) \subset B\left(c, 2^{-k}\right) .
$$

We will now prove

$$
B\left(e_{k},(1 / 4) 2^{-k}\right) \subset B\left(a, 2^{-m}-2^{-(k+1)}\right) .
$$

If $\left|x-e_{k}\right| \leqq(1 / 4) 2^{-k}$ then the definition of $e_{k}$ and (2.4) yield

$$
|x-a| \leqq\left|x-e_{k}\right|+\left|e_{k}-a\right| \leqq(1 / 4) 2^{-k}+\left(|a-c|-(3 / 4) 2^{-k}\right)<2^{-m}-2^{-(k+1)} .
$$

The above proves (2.11). Now we will prove

$$
B\left(c, 2^{-k}\right) \subset A\left(a, 2^{-m}, 2^{-k+2}\right) \text { if } k \leqq n+1 .
$$

Suppose $|x-c| \leqq 2^{-k}$. Then (2.4) yields

$$
|x-a| \leqq|c-a|+|x-c|<2^{-m}+2^{-k}<2^{-m}+2^{-k+2} .
$$

In addition, (2.6) and $k \leqq n+1$ yield

$$
\begin{aligned}
|x-a| & \geqq|c-a|-|x-c| \\
& \geqq 2^{-m}-2^{-n}-2^{-k} \geqq 2^{-m}-2^{-k+1}-2^{-k}>2^{-m}-2^{-k+2} .
\end{aligned}
$$

The above proves (2.12). Now we show

$$
B\left(c, 2^{-k}\right) \subset B\left(a, 2^{-m}-2^{-(n+2)}\right) \quad \text { if } k \geqq n+2 .
$$

If $|x-c| \leqq 2^{-k}$ and $k \geqq n+2$ then (2.6) yields

$$
\begin{aligned}
|x-a| & \leqq|c-a|+|x-c|<2^{-m}-2^{-(n+1)}+2^{-k} \\
& \leqq 2^{-m}-2^{-(n+1)}+2^{-(n+2)}=2^{-m}-2^{-(n+2)} .
\end{aligned}
$$

The above proves (2.13). From (2.7) we obtain

$$
d-b+2^{-2 m}>2^{-2(p+1)}>2^{-2(p+2)}+2^{-2(p+2)} .
$$

The above and (2.3) yield

$$
d-2^{-2(p+2)}>b-\left(2^{-2 m}-2^{-2(p+2)}\right)>0 .
$$

Now we are ready to prove (a). We assume

$$
k \leqq n+1 \text { and } k \leqq p+1 .
$$

From (2.11) and (2.15) we obtain

$$
B\left(e_{k},(1 / 4) 2^{-k}\right) \subset B\left(a, 2^{-m}-2^{-(k+1)}\right) \subset B\left(a, 2^{-m}-2^{-(p+2)}\right) .
$$

Now (2.16), (2.5), (2.14), and (2.9) yield

$$
\begin{aligned}
& K\left(e_{k}, d,(1 / 4) 2^{-k}, 2^{-2(p+2)}\right) \\
& \quad C D(d) \cap K\left(a, b, 2^{-m}-2^{-(p+2)}, 2^{-2 m}-2^{-2(p+2)}\right)=D(d) \cap G(p+2) .
\end{aligned}
$$


Observe that the proof of the inclusion in (2.17) forces $2^{-m}-2^{-(p+2)}>0$ and $2^{-2 m}-2^{-2(p+2)}>0$. These conditions are required in Definition 2.1 [and in (2.9)]. This sort of thing will come up several times. Alternatively, we can use Lemma 2.3.

From (2.15), (2.12), (2.5), and (2.14) we obtain

$$
K\left(c, d, 2^{-k}, 2^{-2(p+2)}\right) \subset T\left(a, b, 2^{-m}, 2^{-2 m}, 2^{-k+2}\right) .
$$

From (2.10), (2.14), Lemma 2.2, (2.17), and (2.18) we obtain

$$
\begin{aligned}
& 2^{4 k} I\left(|u|^{2}, K\left(c, d, 2^{-k}, 2^{-2(p+2)}\right)\right) \\
& \leqq 2^{4 k} C 2^{-3 k} 2^{-2(p+2)} M\left(|u|^{2}, K\left(e_{k}, d,(1 / 4) 2^{-k}, 2^{-2(p+2)}\right)\right) \\
&+2^{4 k} C 2^{-2 k} I\left(|D u|^{2}, K\left(c, d, 2^{-k}, 2^{-2(p+2)}\right)\right) \\
& \leqq C 2^{k} 2^{-2 p} M\left(|u|^{2}, D(d) \cap G(p+2)\right) \\
&+C 2^{2 k} I\left(|D u|^{2}, T\left(a, b, 2^{-m}, 2^{-2 m}, 2^{-k+2}\right)\right) .
\end{aligned}
$$

Properties (2.14) and (2.3) imply that $u$ is defined on the sets that appear above. This proves (a).

Now we prove (b). We suppose

$$
n>p, \quad p+2 \leqq k, \text { and } k \leqq n+1 \text {. }
$$

Using (2.19), (2.14), (2.19) again, and (2.3) we obtain

$$
\begin{aligned}
d-2^{-2 k} & \geqq d-2^{-2(p+2)}>b-\left(2^{-2 m}-2^{-2(p+2)}\right) \\
& \geqq b-\left(2^{-2 m}-2^{-2 k}\right)>b-\left(2^{-2 m}-2^{-2(k+1)}\right)>0 .
\end{aligned}
$$

Now (2.11), (2.5), (2.20), and (2.9) yield

$$
\begin{aligned}
K\left(e_{k}, d,(1 / 4) 2^{-k}, 2^{-2 k}\right) & \\
& C D(d) \cap K\left(a, b, 2^{-m}-2^{-(k+1)}, 2^{-2 m}-2^{-2(k+1)}\right) \\
= & D(d) \cap G(k+1) .
\end{aligned}
$$

From (2.19), (2.12), (2.5), and (2.20) we obtain

$$
K\left(c, d, 2^{-k}, 2^{-2 k}\right) \subset T\left(a, b, 2^{-m}, 2^{-2 m}, 2^{-k+2}\right) .
$$

Now (2.10), (2.20), Lemma 2.2, (2.21), and (2.22) yield

$$
\begin{array}{rl}
2^{4 k} & I\left(|u|^{2}, K\left(c, d, 2^{-k}, 2^{-2 k}\right)\right) \\
\leqq & 2^{4 k} C 2^{-3 k} 2^{-2 k} M\left(|u|^{2}, K\left(e_{k}, d,(1 / 4) 2^{-k}, 2^{-2 k}\right)\right) \\
& +2^{4 k} C 2^{-2 k} I\left(|D u|^{2}, K\left(c, d, 2^{-k}, 2^{-2 k}\right)\right) \\
\leqq & C 2^{-k} M\left(|u|^{2}, D(d) \cap G(k+1)\right) \\
& +C 2^{2 k} I\left(|D u|^{2}, T\left(a, b, 2^{-m}, 2^{-2 m}, 2^{-k+2}\right)\right) .
\end{array}
$$

Properties (2.20) and (2.3) imply that $u$ is defined on the sets that appear above. This proves (b).

Now we prove (c). We suppose

$$
n \leqq p, \quad n+2 \leqq k, \text { and } k \leqq p+1 \text {. }
$$


Using (2.23), (2.13), and (2.23) again we obtain

$$
B\left(c, 2^{-k}\right) \subset B\left(a, 2^{-m}-2^{-(n+2)}\right) \subset B\left(a, 2^{-m}-2^{-(p+2)}\right) .
$$

Now (2.24), (2.5), (2.14), and (2.9) yield

$$
\begin{aligned}
& K\left(c, d, 2^{-k}, 2^{-2(p+2)}\right) \\
& \quad C D(d) \cap K\left(a, b, 2^{-m}-2^{-(p+2)}, 2^{-2 m}-2^{-2(p+2)}\right)=D(d) \cap G(p+2) .
\end{aligned}
$$

From (2.25) we obtain

$$
\begin{aligned}
& 2^{4 k} I\left(|u|^{2}, K\left(c, d, 2^{-k}, 2^{-2(p+2)}\right)\right) \\
& \quad \leqq 2^{4 k} C 2^{-3 k} 2^{-2(p+2)} M\left(|u|^{2}, D(d) \cap G(p+2)\right) .
\end{aligned}
$$

Property (2.14) implies that $u$ is defined on the sets that appear above. This proves (c).

Finally, we prove (d). We assume

$$
k \geqq n+2 \text { and } k \geqq p+2 \text {. }
$$

From (2.26), (2.13), and (2.8) we get

$$
B\left(c, 2^{-k}\right) \subset B\left(a, 2^{-m}-2^{-(n+2)}\right) \subset B\left(a, 2^{-m}-2^{-(q+2)}\right) .
$$

From (2.26), (2.14), (2.8), and (2.3) we obtain

$$
\begin{aligned}
d-2^{-2 k} & \geqq d-2^{-2(p+2)}>b-\left(2^{-2 m}-2^{-2(p+2)}\right) \\
& \geqq b-\left(2^{-2 m}-2^{-2(q+2)}\right)>0 .
\end{aligned}
$$

From (2.27), (2.5), (2.28), and (2.9) we obtain

$$
\begin{aligned}
& K\left(c, d, 2^{-k}, 2^{-2 k}\right) \\
& \quad C D(d) \cap K\left(a, b, 2^{-m}-2^{-(q+2)}, 2^{-2 m}-2^{-2(q+2)}\right)=D(d) \cap G(q+2) .
\end{aligned}
$$

From (2.29) we obtain

$$
2^{4 k} I\left(|u|^{2}, K\left(c, d, 2^{-k}, 2^{-2 k}\right)\right) \leqq 2^{4 k} C 2^{-3 k} 2^{-2 k} M\left(|u|^{2}, D(d) \cap G(q+2)\right) .
$$

Property (2.28) implies that $u$ is defined on the sets that appear above. This proves (d). The lemma is proved.

Lemma 2.5. There is an absolute constant $C_{1}$ such that (see (2.9))

$$
\begin{aligned}
& \int_{d-2-2(p+2)}^{d} \int_{R^{3}}|u(x, t)|^{2}\left(|x-c|+(d-t)^{1 / 2}\right)^{-4} d x d t \\
& \leqq \\
& C_{1}\left(\int_{d-2} \int_{-2(p+2)}^{d} \int_{R^{3}}|u(x, t)|^{2}\left(|x-a|+2^{-m}\right)^{-4} d x d t\right) \\
& \quad+\sum_{k=m+1}^{q+1} C_{1} 2^{-k} M\left(|u|^{2}, D(d) \cap G(k+1)\right) \\
& +\sum_{k=m+1}^{q+1} C_{1} 2^{2 k} I\left(|D u|^{2}, T\left(a, b, 2^{-m}, 2^{-2 m}, 2^{-k+2}\right)\right) .
\end{aligned}
$$


Proof. For every integer $k$ we define $E(k)$ by

$$
E(k)=K\left(c, d, 2^{-k}, 2^{-2(p+2)}\right) \sim K\left(c, d, 2^{-(k+1)}, 2^{-2(p+2)}\right)
$$

if $k \leqq p+1$, and

$$
E(k)=K\left(c, d, 2^{-k}, 2^{-2 k}\right) \sim K\left(c, d, 2^{-(k+1)}, 2^{-2(k+1)}\right)
$$

if $k \geqq p+2$. We have

$$
\left\{(x, t): d-2^{-2(p+2)} \leqq t \leqq d\right\} \sim\{(c, d)\}=\bigcup_{k=-\infty}^{\infty} E(k) .
$$

Now we will prove

$$
\left(|x-c|+(d-t)^{1 / 2}\right)^{-4}<2^{4(k+1)} \quad \text { if } \quad(x, t) \in E(k) .
$$

If $k \leqq p+1$ and $(x, t) \in E(k)$ then $|x-c|>2^{-(k+1)}$ and (2.33) follows. If $k \geqq p+2$ and $(x, t) \in E(k)$ then either $|x-c|>2^{-(k+1)}$ or $d-t>2^{-2(k+1)}$. In either case, (2.33) follows. From (2.32) and (2.33) we obtain

$$
\begin{aligned}
& \int_{d-2(p+2)}^{d} \int_{R^{3}}|u(x, t)|^{2}\left(|x-c|+(d-t)^{1 / 2}\right)^{-4} d x d t \\
& \leqq \sum_{k=-\infty}^{\infty} 2^{4(k+1)} I\left(|u|^{2}, E(k)\right) .
\end{aligned}
$$

Next we prove

$$
\begin{aligned}
& \sum_{k=-\infty}^{m+1} 2^{4(k+1)} I\left(|u|^{2}, E(k)\right) \\
& \quad \leqq C\left(\int_{d-2}^{d} \int_{R^{3}(p+2)}|u(x, t)|^{2}\left(|x-a|+2^{-m}\right)^{-4} d x d t\right) .
\end{aligned}
$$

Since the $E(k)$ are disjoint and (2.32) holds, it suffices to show

$$
2^{4(k+1)} \leqq C\left(|x-a|+2^{-m}\right)^{-4} \quad \text { if } \quad k \leqq m+1 \quad \text { and } \quad(x, t) \in E(k) .
$$

Suppose $k \leqq m+1$ and $(x, t) \in E(k)$. Then Lemma 2.3 and (2.30) yield $|x-c| \leqq 2^{-k}$. Hence (2.4) implies

$$
\begin{aligned}
|x-a|+2^{-m} & \leqq|x-c|+|c-a|+2^{-m}<2^{-k}+2^{-m}+2^{-m} \\
& \leqq 2^{-k}+2^{-k+2}<2^{-k+3}
\end{aligned}
$$

Hence (2.36) holds, and this implies (2.35).

There are two possibilities: Either $|a-c| \leqq 2^{-(m+1)}$ or $2^{-(m+1)}<|a-c|$. First we examine the case

$$
|a-c| \leqq 2^{-(m+1)} .
$$

We will prove

$$
B\left(c, 2^{-k}\right) \subset B\left(a, 2^{-m}-2^{-(p+2)}\right) \quad \text { if } \quad k \geqq m+2 .
$$


If $k \geqq m+2$ then Lemma 2.3 implies

$$
2^{-k}+2^{-(p+2)} \leqq 2^{-(m+2)}+2^{-(m+2)}=2^{-(m+1)} .
$$

Hence (2.37) implies that every $x \in B\left(c, 2^{-k}\right)$ satisfies

$$
\begin{aligned}
|x-a| & \leqq|x-c|+|c-a| \leqq 2^{-k}+2^{-(m+1)} \\
& =2^{-k}+2^{-m}-2^{-(m+1)} \leqq 2^{-m}-2^{-(p+2)} .
\end{aligned}
$$

Hence (2.38) holds. The argument that gave us (2.14) still yields

$$
d-2^{-2(p+2)}>b-\left(2^{-2 m}-2^{-2(p+2)}\right)>0
$$

since the hypotheses of Lemma 2.4 were not used in the proof of (2.14).

Now (2.5), (2.30)-(2.32), (2.38), (2.39), and (2.9) imply

$$
E(k) \subset D(d) \cap K\left(a, b, 2^{-m}-2^{-(p+2)}, 2^{-2 m}-2^{-2(p+2)}\right)=D(d) \cap G(p+2)
$$

if $k \geqq m+2$. From Lemma 2.3, (2.30), (2.31), and (2.40) we obtain

$$
\begin{aligned}
& \sum_{k=m+2}^{\infty} 2^{4 k} I\left(|u|^{2}, E(k)\right) \\
& =\sum_{k=m+2}^{p+1} 2^{4 k} I\left(|u|^{2}, E(k)\right)+\sum_{k=p+2}^{\infty} 2^{4 k} I\left(|u|^{2}, E(k)\right) \\
& \leqq \sum_{k=m+2}^{p+1} 2^{4 k} C 2^{-3 k} 2^{-2(p+2)} M\left(|u|^{2}, D(d) \cap G(p+2)\right) \\
& +\sum_{k=p+2}^{\infty} 2^{4 k} C 2^{-3 k} 2^{-2 k} M\left(|u|^{2}, D(d) \cap G(p+2)\right) \\
& \leqq C 2^{-p} M\left(|u|^{2}, D(d) \cap G(p+2)\right) .
\end{aligned}
$$

From Lemma 2.3 and (2.8) we get $m+1 \leqq p+1 \leqq q+1$. Hence (2.34), (2.35), and (2.41) yield the conclusion of the lemma if possibility (2.37) holds.

The second possibility we must examine is

$$
2^{-(m+1)}<|a-c| .
$$

Now we have two cases: Either $n \leqq p$ or $n>p$. Assume first that $n \leqq p$ holds. Then (2.42), (2.30), (2.31), parts (a), (c), (d) of Lemma 2.4, (2.8), and $p=q$ [which follows from $n \leqq p$ and (2.8)] yield

$$
\begin{aligned}
& \sum_{k=m+1}^{\infty} 2^{4 k} I\left(|u|^{2}, E(k)\right) \\
& =\sum_{k=m+1}^{n+1} 2^{4 k} I\left(|u|^{2}, E(k)\right)+\sum_{k=n+2}^{p+1} 2^{4 k} I\left(|u|^{2}, E(k)\right) \\
& \quad+\sum_{k=p+2}^{\infty} 2^{4 k} I\left(|u|^{2}, E(k)\right)
\end{aligned}
$$




$$
\begin{aligned}
\leqq & \sum_{k=m+1}^{n+1} C 2^{k} 2^{-2 p} M\left(|u|^{2}, D(d) \cap G(p+2)\right) \\
& +\sum_{k=m+1}^{n+1} C 2^{2 k} I\left(|D u|^{2}, T\left(a, b, 2^{-m}, 2^{-2 m}, 2^{-k+2}\right)\right) \\
& +\sum_{k=n+2}^{p+1} C 2^{k} 2^{-2 p} M\left(|u|^{2}, D(d) \cap G(p+2)\right) \\
& +\sum_{k=p+2}^{\infty} C 2^{-k} M\left(|u|^{2}, D(d) \cap G(q+2)\right) \\
\leqq & C 2^{p} 2^{-2 p} M\left(|u|^{2}, D(d) \cap G(p+2)\right) \\
& +\sum_{k=m+1}^{q+1} C 2^{2 k} I\left(|D u|^{2}, T\left(a, b, 2^{-m}, 2^{-2 m}, 2^{-k+2}\right)\right) \\
& +C 2^{-p} M\left(|u|^{2}, D(d) \cap G(q+2)\right) \\
= & C 2^{-q} M\left(|u|^{2}, D(d) \cap G(q+2)\right) \\
& +\sum_{k=m+1}^{q+1} C 2^{2 k} I\left(|D u|^{2}, T\left(a, b, 2^{-m}, 2^{-2 m}, 2^{-k+2}\right)\right) .
\end{aligned}
$$

From (2.8) and Lemma 2.3 we get $m+1 \leqq q+1$. Hence (2.34), (2.35), and (2.43) yield the conclusion of the lemma if possibilities (2.42) and $n \leqq p$ hold.

Now we consider the case where (2.42) and $n>p$ hold. Then (2.42), (2.30), (2.31), parts (a), (b), (d) of Lemma 2.4, Lemma 2.3, $q=n$ [which follows from $n>p$ and (2.8)], and $m+1 \leqq p+1 \leqq q+1$ [which follows from Lemma 2.3 and (2.8)] imply

$$
\begin{aligned}
& \sum_{k=m+1}^{\infty} 2^{4 k} I\left(|u|^{2}, E(k)\right) \\
& =\sum_{k=m+1}^{p+1} 2^{4 k} I\left(|u|^{2}, E(k)\right)+\sum_{k=p+2}^{n+1} 2^{4 k} I\left(|u|^{2}, E(k)\right) \\
& \quad+\sum_{k=n+2}^{\infty} 2^{4 k} I\left(|u|^{2}, E(k)\right) \\
& \leqq \\
& \quad \sum_{k=m+1}^{p+1} C 2^{k} 2^{-2 p} M\left(|u|^{2}, D(d) \cap G(p+2)\right) \\
& \quad+\sum_{k=m+1}^{p+1} C 2^{2 k} I\left(|D u|^{2}, T\left(a, b, 2^{-m}, 2^{-2 m}, 2^{-k+2}\right)\right) \\
& \quad+\sum_{k=p+2}^{n+1} C 2^{-k} M\left(|u|^{2}, D(d) \cap G(k+1)\right) \\
& \quad+\sum_{k=p+2}^{n+1} C 2^{2 k} I\left(|D u|^{2}, T\left(a, b, 2^{-m}, 2^{-2 m}, 2^{-k+2}\right)\right) \\
& \quad+\sum_{k=n+2}^{\infty} C 2^{-k} M\left(|u|^{2}, D(d) \cap G(q+2)\right)
\end{aligned}
$$




$$
\begin{aligned}
\leqq & C 2^{p} 2^{-2 p} M\left(|u|^{2}, D(d) \cap G(p+2)\right) \\
& +\sum_{k=m+1}^{n+1} C 2^{-k} M\left(|u|^{2}, D(d) \cap G(k+1)\right) \\
& +\sum_{k=m+1}^{n+1} C 2^{2 k} I\left(|D u|^{2}, T\left(a, b, 2^{-m}, 2^{-2 m}, 2^{-k+2}\right)\right) \\
& +C 2^{-n} M\left(|u|^{2}, D(d) \cap G(q+2)\right) \\
\leqq & C 2^{-(p+1)} M\left(|u|^{2}, D(d) \cap G(p+2)\right) \\
& +\sum_{k=m+1}^{q+1} C 2^{-k} M\left(|u|^{2}, D(d) \cap G(k+1)\right) \\
& +C 2^{-(q+1)} M\left(|u|^{2}, D(d) \cap G(q+2)\right) \\
& +\sum_{k=m+1}^{q+1} C 2^{2 k} I\left(|D u|^{2}, T\left(a, b, 2^{-m}, 2^{-2 m}, 2^{-k+2}\right)\right) \\
\leqq & \sum_{k=m+1}^{q+1} C 2^{-k} M\left(|u|^{2}, D(d) \cap G(k+1)\right) \\
& +\sum_{k=m+1}^{q+1} C 2^{2 k} I\left(|D u|^{2}, T\left(a, b, 2^{-m}, 2^{-2 m}, 2^{-k+2}\right)\right) .
\end{aligned}
$$

The conclusion of the lemma in this case follows from (2.34), (2.35), and (2.44). Lemma 2.5 has been proved.

Lemma 2.6. If $f: R^{3} \rightarrow R, f \in L^{2}$, and $D f \in L^{2}$ then

$$
\begin{aligned}
& \left(\int_{B(x, r)}|f(y)|^{3} d y\right)^{1 / 3} \\
& \quad \leqq C r^{-1 / 2}\left(\int_{B(x, 2 r)}|f(y)|^{2} d y\right)^{1 / 2}+C r^{1 / 2}\left(\int_{B(x, 2 r)}|D f(y)|^{2} d y\right)^{1 / 2} .
\end{aligned}
$$

Proof. Let $g: R^{3} \rightarrow[0,1]$ be a smooth function such that $g(y)=1$ for $y \in B(x, r)$, $g(y)=0$ for $y \notin B(x, 2 r)$, and $\|D g\|_{\infty} \leqq C r^{-1}$. Set $h(y)=g(y) f(y)$. Using the argument in Lemma 3.1 of [5] and Young's inequality we obtain

$$
\begin{aligned}
& \left(\int_{B(x, r)}|f(y)|^{3} d y\right)^{1 / 3} \leqq\left(\int_{R^{3}}|h(y)|^{3} d y\right)^{1 / 3} \\
& \leqq C\left(\int_{R^{3}}|h(y)|^{2} d y\right)^{1 / 4}\left(\int_{R^{3}}|D h(y)|^{2} d y\right)^{1 / 4} \\
& \leqq C r^{-1 / 2}\left(\int_{R^{3}}|h(y)|^{2} d y\right)^{1 / 2}+C r^{1 / 2}\left(\int_{R^{3}}|D h(y)|^{2} d y\right)^{1 / 2} \\
& \leqq C r^{-1 / 2}\left(\int_{B(x, 2 r)}|f(y)|^{2} d y\right)^{1 / 2}+C r^{1 / 2}\left(\int_{B(x, 2 r)}|D g(y)|^{2}|f(y)|^{2} d y\right)^{1 / 2} \\
& \left.\quad+C r^{1 / 2}\left(\int_{B(x, 2 r)}|g(y)|^{2}|D f(y)|^{2} d y\right)^{1 / 2} r_{B(x, 2 r)}|f(y)|^{2} d y\right)^{1 / 2}+C r^{1 / 2}\left(\underset{B(x, 2 r)}{\left.\int_{(1 / 2}|D f(y)|^{2} d y\right)^{1 / 2} .}\right.
\end{aligned}
$$


Lemma 2.7. If $0<h \leqq 2^{-m}$ then for almost every $t>0$ we have

$$
\begin{aligned}
& \int_{R^{3}}|u(x, t)|(|x-c|+h)^{-4} h^{-1} d x \\
& \leqq C 2^{-3 m / 2} h^{-3}\left(\int_{R^{3}}|u(x, t)|^{2}\left(|x-a|+2^{-m}\right)^{-4} d x\right)^{1 / 2} \\
&+C 2^{-m / 2} h^{-3}\left(\int_{B\left(a, 2^{-m+2}\right)}|D u(x, t)|^{2} d x\right)^{1 / 2} .
\end{aligned}
$$

Proof. From Hölder's inequality, the conditions on $h,(2.1),(2.2)$, Lemma 2.6, and (2.4) we obtain the following for almost every $t>0$ :

$$
\begin{aligned}
& \int_{B\left(c, 2^{-m}\right)}|u(x, t)|(|x-c|+h)^{-4} h^{-1} d x \\
& \leqq\left(\int_{B\left(c, 2^{-m}\right)}|u(x, t)|^{3} d x\right)^{1 / 3}\left(\int_{B\left(c, 2^{-m}\right)}\left((|x-c|+h)^{-4} h^{-1}\right)^{3 / 2} d x\right)^{2 / 3} \\
& \leqq\left.C \int_{B\left(c, 2^{-m}\right)}|u(x, t)|^{3} d x\right)^{1 / 3} h^{-3} \\
& \leqq C 2^{m / 2}\left(\int_{B\left(c, 2^{-m+1}\right)}|u(x, t)|^{2} d x\right)^{1 / 2} h^{-3} \\
&+C 2^{-m / 2}\left(\int_{B\left(c, 2^{-m+1)}\right.}|D u(x, t)|^{2} d x\right)^{1 / 2} h^{-3} \\
& \leqq C 2^{m / 2} h^{-3}\left(\int_{B\left(a, 2^{-m+2)}\right.}|u(x, t)|^{2} d x\right)^{1 / 2} \\
&+C 2^{-m / 2} h^{-3}\left(\int_{B\left(a, 2^{-m+2)}\right.}|D u(x, t)|^{2} d x\right)^{1 / 2} .
\end{aligned}
$$

Let $E=\left\{x \in R^{3}: x \notin B\left(c, 2^{-m}\right)\right\}$. If $x \in E$ then (2.4) yields

$$
\begin{aligned}
|x-a|+2^{-m} & <(|x-c|+|c-a|)+|x-c| \\
& <|x-c|+2^{-m}+|x-c|<3|x-c|<3(|x-c|+h) .
\end{aligned}
$$

Hence the Schwarz inequality and $0<h \leqq 2^{-m}$ yield

$$
\begin{aligned}
& \int_{E}|u(x, t)|(|x-c|+h)^{-4} h^{-1} d x \\
& \leqq C h^{-1}\left(\int_{E}|u(x, t)|\left(|x-a|+2^{-m}\right)^{-4} d x\right) \\
& \leqq C h^{-1}\left(\int_{R^{3}}\left(|u(x, t)|\left(|x-a|+2^{-m}\right)^{-2}\right)\left(|x-a|+2^{-m}\right)^{-2} d x\right) \\
& \leqq C h^{-1}\left(\int_{R^{3}}|u(x, t)|^{2}\left(|x-a|+2^{-m}\right)^{-4} d x\right)^{1 / 2}\left(\int_{R^{3}}\left(|x-a|+2^{-m}\right)^{-4} d x\right)^{1 / 2} \\
& \leqq C h^{-1} 2^{m / 2}\left(\int_{R^{3}}|u(x, t)|^{2}\left(|x-a|+2^{-m}\right)^{-4} d x\right)^{1 / 2} \\
& \leqq C h^{-3} 2^{-3 m / 2}\left(\int_{R^{3}}|u(x, t)|^{2}\left(|x-a|+2^{-m}\right)^{-4} d x\right)^{1 / 2}
\end{aligned}
$$

If $x \in B\left(a, 2^{-m+2}\right)$ then

$$
\left(|x-a|+2^{-m}\right)^{-4} 2^{-4 m} \geqq\left(2^{-m+2}+2^{-m}\right)^{-4} 2^{-4 m}>2^{-12} .
$$


Hence

$$
\begin{aligned}
& \left(\int_{B\left(a, 2^{-m+2)}\right.}|u(x, t)|^{2} d x\right)^{1 / 2} \\
& \quad \leqq C\left(\int_{B\left(a, 2^{-m+2)}\right.}|u(x, t)|^{2}\left(|x-a|+2^{-m}\right)^{-4} 2^{-4 m} d x\right)^{1 / 2} \\
& \quad=2^{-2 m} C\left(\int_{R^{3}}|u(x, t)|^{2}\left(|x-a|+2^{-m}\right)^{-4} d x\right)^{1 / 2}
\end{aligned}
$$

The conclusion follows from (2.45), (2.46), and (2.47).

Lemma 2.8. There exists an absolute constant $C_{2}$ such that the following holds: If $h=2^{-(p+2)}$ then

$$
\begin{aligned}
& \int_{d-h^{2}}^{d} \int_{R^{3}}|u(x, t)|(|x-c|+h)^{-4} h^{-1} d x d t \\
& \leqq C_{2} 2^{-3 m / 2} h^{-2}\left(\int_{d-h^{2}}^{d} \int_{R^{3}}|u(x, t)|^{2}\left(|x-a|+2^{-m}\right)^{-4} d x d t\right)^{1 / 2} \\
& \quad+C_{2} 2^{-m / 2} h^{-2}\left(\int_{d-h^{2}}^{d} \int_{B\left(a, 2^{-m+2)}\right.}|D u(x, t)|^{2} d x d t\right)^{1 / 2} .
\end{aligned}
$$

Proof. The hypothesis of Lemma 2.7 is satisfied because of Lemma 2.3. Now use Lemma 2.7, (2.14), and the estimate

$$
\int_{d-h^{2}}^{d}|f(t)|^{1 / 2} d t \leqq h\left(\int_{d-h^{2}}^{d}|f(t)| d t\right)^{1 / 2},
$$

which follows from the Schwarz inequality.

\section{3.}

We continue to use the notation introduced in Definition 2.1 and (2.9) and we assume that $u: R^{3} \times R^{+} \rightarrow R^{3}$ is a continuous function satisfying (2.1) and (2.2).

Lemma 3.1. For every $H>0$ there exist positive constants $C_{3}(H)$ and $C_{4}(H)$, which depend only on $H$, such that the following is satisfied. Suppose we have the following conditions : $a \in R^{3}, b \in R^{+}, m$ is an integer, $b>2^{-2 m}, \Gamma \in R^{+}$, the inequality

$$
\begin{aligned}
H^{-1}|u(c, d)| \leqq & \int_{d-h^{2}}^{d} \int_{R^{3}}|u(x, t)|^{2}\left(|x-c|+(d-t)^{1 / 2}\right)^{-4} d x d t \\
& +\int_{d-h^{2}}^{d} \int_{R^{3}}|u(x, t)|(|x-c|+h)^{-4} h^{-1} d x d t+\Gamma
\end{aligned}
$$

holds whenever $(c, d) \in K\left(a, b, 2^{-m}, 2^{-2 m}\right), 0<h \leqq 2^{-m}$, and $d>h^{2}$,

$$
\begin{aligned}
& I\left(|D u|^{2}, T\left(a, b, 2^{-m}, 2^{-2 m}, r\right)\right) \leqq C_{3}(H) r \quad \text { if } \quad 0<r \leqq 2^{-m+1}, \\
& I\left(|D u|^{2}, K\left(a, b-2^{-2 m}+s, 2^{-m+2}, s\right)\right) \leqq C_{3}(H) 2^{m} S \quad \text { if } \quad 0<s \leqq 2^{-2 m}, \\
& \int_{b-2-2 m}^{b-2 m+s} \int_{R^{3}}|u(x, t)|^{2}\left(|x-a|+2^{-m}\right)^{-4} d x d t \leqq C_{3}(H) 2^{3 m} S
\end{aligned}
$$


holds whenever $0<s \leqq 2^{-2 m}$, and

$$
\Gamma \leqq C_{3}(H) 2^{m} .
$$

Then we can conclude

$$
|u(x, t)| \leqq C_{4}(H) 2^{m+1} \quad \text { if } \quad(x, t) \in K\left(a, b, 2^{-(m+1)}, 2^{-2 m}(3 / 4)\right) .
$$

Proof. We choose $C_{4}(H)>0$ so that (3.7) holds (see Lemma 2.5):

$$
2^{4} C_{1}\left(C_{4}(H)\right)^{2} \leqq(1 / 4) H^{-1} C_{4}(H) .
$$

Then we choose $C_{3}(H)>0$ so that (3.8) holds (see Lemmas 2.5 and 2.8):

$$
\begin{aligned}
& C_{1} C_{3}(H)+2^{4} C_{1} C_{3}(H)+2^{5} C_{2}\left(C_{3}(H)\right)^{1 / 2} \leqq(1 / 4) H^{-1} C_{4}(H), C_{3}(H) \\
\leqq & (1 / 4) H^{-1} C_{4}(H) .
\end{aligned}
$$

For every integer $i$ satisfying $i \geqq m+1$ we define $Z(i)$ to be the union of

$$
\left\{(x, t) \in R^{3} \times R:|x-a|=2^{-m}-2^{-i}, b-2^{-2 m}+2^{-2 i} \leqq t \leqq b\right\}
$$

and

$$
\left\{(x, t) \in R^{3} \times R:|x-a| \leqq 2^{-m}-2^{-i}, t=b-2^{-2 m}+2^{-2 i}\right\} .
$$

If $i$ is an integer and $i \geqq m+2$ we define $Y(i)$ to be the closure of $G(i) \sim G(i-1)$ [see (2.9)]. We also set $Y(m+1)=G(m+1)$. We obtain that $Y(i) \cap Y(j)$ is empty if $|i-j| \geqq 2$. We also obtain $Y(i) \cap Y(i+1)=Z(i)$. Set $P=\bigcup_{i=m+1}^{\infty} Y(i)$. We define a function $f: P \rightarrow R^{+}$as follows: If $(x, t) \in Z(i)$ then $f(x, t)=C_{4}(H) 2^{i}$. If $i \geqq m+2$ we use the Urysohn theorem to extend this definition of $f$ continuously to $Y(i)$ so that $C_{4}(H) 2^{i} \geqq f(x, t) \geqq C_{4}(H) 2^{i-1}$ whenever $(x, t) \in Y(i)$. Finally, we set $f(x, t)$ $=C_{4}(H) 2^{m+1}$ if $(x, t) \in Y(m+1)$. We have the following properties for every $(x, t) \in P$ and any integer $i \geqq m+1$ :

$$
\begin{aligned}
& \text { If }(x, t) \in G(i) \text { then } f(x, t) \leqq C_{4}(H) 2^{i}, \\
& \text { if }|x-a| \geqq 2^{-m}-2^{-i} \text { or } t \leqq b-2^{-2 m}+2^{-2 i} \text { then } f(x, t) \geqq C_{4}(H) 2^{i} .
\end{aligned}
$$

We intend to show

$$
|u(x, t)| \leqq f(x, t) \text { for all }(x, t) \in P .
$$

If (3.11) is false then the set $S=\{(x, t) \in P:|u(x, t)| \geqq f(x, t)\}$ is nonempty. Since $u$ is continuous, $u$ is bounded on the compact set $K\left(a, b, 2^{-m}, 2^{-2 m}\right)$. Hence there exists an integer $i \geqq m+1$ such that $|u(x, t)|<C_{4}(H) 2^{i}$ for all $(x, t) \in P$. Hence (3.10) yields $S \subset G(i)$. Since $G(i)$ is compact and the functions $u$ and $f$ are continuous, we conclude that $S$ is compact. Hence there exists $(c, d) \in P$ such that

$$
\begin{aligned}
& |u(c, d)| \geqq f(c, d), \\
& |u(x, t)| \leqq f(x, t) \quad \text { if } \quad(x, t) \in P \quad \text { and } \quad t \leqq d .
\end{aligned}
$$


From the hypotheses we obtain that (2.1)-(2.3) are satisfied. From $(c, d) \in P$ we conclude that (2.4), (2.5) hold. We define the integers $n$ and $p$ by (2.6), (2.7) [this determines $n$ and $p$ uniquely in view of (2.4), (2.5)]. We also define $q$ by (2.8). Hence all the hypotheses of Sect. 2 are satisfied. Using $h=2^{-(p+2)}$ and observing that $d>h^{2}$ follows from (2.3) and (2.7), and that $h \leqq 2^{-m}$ follows from Lemma 2.3, we obtain (3.14) from (3.1), Lemma 2.5, and Lemma 2.8:

$$
\begin{aligned}
& H^{-1}|u(c, d)| \\
& \leqq C_{1}\left(\int_{d-2}^{d} \int_{-2(p+2)}|u(x, t)|^{2}\left(|x-a|+2^{-m}\right)^{-4} d x d t\right) \\
& +\sum_{k=m+1}^{q+1} C_{1} 2^{-k} M\left(|u|^{2}, D(d) \cap G(k+1)\right) \\
& +\sum_{k=m+1}^{q+1} C_{1} 2^{2 k} I\left(|D u|^{2}, T\left(a, b, 2^{-m}, 2^{-2 m}, 2^{-k+2}\right)\right) \\
& +C_{2} 2^{-3 m / 2} 2^{2(p+2)}\left(\int_{d-2^{-2(p+2)}}^{d} \int_{R^{3}}|u(x, t)|^{2}\left(|x-a|+2^{-m}\right)^{-4} d x d t\right)^{1 / 2} \\
& +C_{2} 2^{-m / 2} 2^{2(p+2)}\left(\int_{d-2}^{d} \int_{-2(p+2)}^{d\left(a, 2^{-m+2)}\right.}|D u(x, t)|^{2} d x d t\right)^{1 / 2}+\Gamma .
\end{aligned}
$$

From (2.6) we obtain $|a-c| \geqq 2^{-m}-2^{-n}$. From (2.7) we obtain $d \leqq b-2^{-2 m}+2^{-2 p}$. Hence (2.8) implies that either $|a-c| \geqq 2^{-m}-2^{-q}$ or $d \leqq b-2^{-2 m}+2^{-2 q}$ must hold. If $q \geqq m+1$ then (3.10) yields $f(c, d) \geqq C_{4}(H) 2^{q}$. If $q=m$ then $f(c, d) \geqq C_{4}(H) 2^{q}$ still follows because $f(x, t) \geqq C_{4}(H) 2^{m+1}$ holds for all $(x, t) \in P$. Since Lemma 2.3 and (2.8) imply $q \geqq m$, we can use (3.12) to conclude

$$
C_{4}(H) 2^{q} \leqq f(c, d) \leqq|u(c, d)| .
$$

From (3.9) and (3.13) we conclude

$$
\begin{aligned}
& \sum_{k=m+1}^{q+1} C_{1} 2^{-k} M\left(|u|^{2}, D(d) \cap G(k+1)\right) \\
& \leqq \sum_{k=m+1}^{q+1} C_{1} 2^{-k}\left(C_{4}(H) 2^{k+1}\right)^{2}<2^{q+4} C_{1}\left(C_{4}(H)\right)^{2} .
\end{aligned}
$$

From (3.2) we obtain

$$
\begin{aligned}
& \sum_{k=m+1}^{q+1} C_{1} 2^{2 k} I\left(|D u|^{2}, T\left(a, b, 2^{-m}, 2^{-2 m}, 2^{-k+2}\right)\right) \\
& \leqq \sum_{k=m+1}^{q+1} C_{1} 2^{2 k} C_{3}(H) 2^{-k+2}<2^{q+4} C_{1} C_{3}(H) .
\end{aligned}
$$


Setting $s=d-\left(b-2^{-2 m}\right)$, we use (2.5), (2.7), and Lemma 2.3 to obtain $0<s \leqq 2^{-2 p}$ $\leqq 2^{-2 m}, d-2^{-2(p+2)}>b-2^{-2 m}$. Hence (3.4) and (3.3) yield

$$
\begin{aligned}
& \int_{d-2}^{d} \int_{-2(p+2)}|u(x, t)|^{2}\left(|x-a|+2^{-m}\right)^{-4} d x d t \\
& b-2-2 m+s \\
& \leqq \int_{b-2-2 m} \int_{R^{3}}|u(x, t)|^{2}\left(|x-a|+2^{-m}\right)^{-4} d x d t \\
& \leqq C_{3}(H) 2^{3 m} S \leqq C_{3}(H) 2^{3 m} 2^{-2 p} \text {, } \\
& \int_{d-2-2(p+2)}^{d} \int_{B\left(a, 2^{-m+2)}\right.}|D u(x, t)|^{2} d x d t \\
& \leqq \int_{b-2-2 m}^{b-2-2 m+s} \int_{B\left(a, 2^{-m+2)}\right.}|D u(x, t)|^{2} d x d t \\
& =I\left(|D u|^{2}, K\left(a, b-2^{-2 m}+s, 2^{-m+2}, s\right)\right) \leqq C_{3}(H) 2^{m} S \leqq C_{3}(H) 2^{m} 2^{-2 p} .
\end{aligned}
$$

Combining (3.14)-(3.19), (3.5), and $q \geqq m$ [which follows from (2.8) and Lemma 2.3] we conclude

$$
\begin{aligned}
H^{-1} C_{4}(H) 2^{q} \leqq & C_{1} C_{3}(H) 2^{3 m} 2^{-2 p}+2^{q+4} C_{1}\left(C_{4}(H)\right)^{2}+2^{q+4} C_{1} C_{3}(H) \\
& +C_{2} 2^{-3 m / 2} 2^{2(p+2)}\left(C_{3}(H) 2^{3 m} 2^{-2 p}\right)^{1 / 2} \\
& +C_{2} 2^{-m / 2} 2^{2(p+2)}\left(C_{3}(H) 2^{m} 2^{-2 p}\right)^{1 / 2}+C_{3}(H) 2^{q}
\end{aligned}
$$

From Lemma 2.3 and (2.8) we get $2^{3 m} 2^{-2 p} \leqq 2^{p} \leqq 2^{q}, p \leqq q$. Using this in (3.20) and dividing by $2^{q}$ we get

$$
\begin{aligned}
H^{-1} C_{4}(H) \leqq & C_{1} C_{3}(H)+2{ }^{4} C_{1}\left(C_{4}(H)\right)^{2}+2{ }^{4} C_{1} C_{3}(H)+2{ }^{4} C_{2}\left(C_{3}(H)\right)^{1 / 2} \\
& +2^{4} C_{2}\left(C_{3}(H)\right)^{1 / 2}+C_{3}(H) .
\end{aligned}
$$

However, (3.21) contradicts (3.7) and (3.8). This contradiction was obtained by assuming that (3.11) is false. Now (3.6) follows from (3.11) and the substitution of $i=m+1$ in (3.9).

\section{4.}

As in Sect. 3, we assume that $u: R^{3} \times R^{+} \rightarrow R^{3}$ is a continuous function satisfying (2.1) and (2.2). The notation comes from Sect. 2.

Lemma 4.1. Suppose that $a \in R^{3}, b \in R^{+}, m$ is an integer, and $b>2^{-2 m}$. Then there exists a number e such that $1 / 2<e<1$ and the following holds: If $v: R^{3} \times R^{+} \rightarrow R^{3}$ is defined by $v(x, t)=e\left(u\left(e x, e^{2} t\right)\right), a^{\prime}=e^{-1} a$, and $b^{\prime}=e^{-2} b$ then

$$
\begin{aligned}
& I\left(|D v|^{2}, T\left(a^{\prime}, b^{\prime}, 2^{-m}, 2^{-2 m}, r\right)\right) \\
& \quad \leqq(80) 2^{m} r\left(I\left(|D u|^{2}, K\left(a, b, 2^{-m+2}, 2^{-2 m}\right)\right)\right) \quad \text { if } \quad 0<r \leqq 2^{-m+1}, \\
& I\left(|D v|^{2}, K\left(a^{\prime}, b^{\prime}-2^{-2 m}+s, 2^{-m+2}, s\right)\right) \\
& \quad \leqq(80) 2^{2 m} s\left(I\left(|D u|^{2}, K\left(a, b, 2^{-m+2}, 2^{-2 m}\right)\right)\right) \quad \text { if } \quad 0<s \leqq 2^{-2 m},
\end{aligned}
$$


and

$$
\begin{aligned}
& \int_{b^{\prime}-2^{-2 m}}^{b^{\prime}-2-2 m+s} \int_{R^{3}}|v(x, t)|^{2}\left(\left|x-a^{\prime}\right|+2^{-m}\right)^{-4} d x d t \\
& \leqq(160) 2^{2 m} S\left(\int_{b-2^{-2 m}}^{b} \int_{R^{3}}|u(x, t)|^{2}\left(|x-a|+2^{-m}\right)^{-4} d x d t\right) \text { if } 0<s \leqq 2^{-2 m}
\end{aligned}
$$

Proof. Define $g_{1}: R \rightarrow R$ as follows: If $h \leqq 0$ or $h \geqq 2^{-m+2}$ then $g_{1}(h)=0$. If $0<h<2^{-m+2}$ then $g_{1}(h)$ is the integral of $|D u(x, t)|^{2}$ over the set

$$
\left\{(x, t):|x-a|=h, b-2^{-2 m} \leqq t \leqq b\right\}
$$

with respect to the 3 dimensional measure on that set. We obtain

$$
\begin{aligned}
\left\|g_{1}\right\|_{1} & =I\left(|D u|^{2}, K\left(a, b, 2^{-m+2}, 2^{-2 m}\right)\right), \\
\int_{h-r}^{h+r} g_{1}(y) d y & =I\left(|D u|^{2}, T\left(a, b, h, 2^{-2 m}, r\right)\right)
\end{aligned}
$$

if $0<h \leqq 2^{-m}$ and $0<r \leqq 2^{-m+1}$. For any integrable function $f: R \rightarrow R^{+}$we define

$$
M f(h)=\sup _{r>0}(2 r)^{-1}\left(\int_{h-r}^{h+r} f(y) d y\right) .
$$

If $S$ is a measurable subset of $R$ we define $m(S)$ to be the Lebesgue measure of $S$. The Hardy-Littlewood theorem ([9], p. 55) says

$$
m\{h \in R: M f(h)>1 / c\} \leqq 5 c\|f\|_{1} .
$$

Hence we obtain $m\left\{h \in R: M g_{1}(h)>2^{m+3}(5)\left\|g_{1}\right\|_{1}\right\} \leqq 2^{-m-3}$ and, consequently,

$$
m\left\{e \in R: M g_{1}\left(2^{-m} e\right)>2^{m+3}(5)\left\|g_{1}\right\|_{1}\right\} \leqq 1 / 8 .
$$

Now define $g_{2}: R \rightarrow R$ and $g_{3}: R \rightarrow R$ as follows: If $t<b-2^{-2 m}$ or $t>b$ then $g_{2}(t)$ $=g_{3}(t)=0$. If $b-2^{-2 m} \leqq t \leqq b$ then

$$
\begin{aligned}
& g_{2}(t)=\int_{R^{3}}|u(x, t)|^{2}\left(|x-a|+2^{-m}\right)^{-4} d x, \\
& g_{3}(t)=\int_{B\left(a, 2^{-m+2)}\right.}|D u(x, t)|^{2} d x .
\end{aligned}
$$

Using (4.3) we obtain

$$
m\left\{t \in R: M g_{i}(t)>(40) 2^{2 m}\left\|g_{i}\right\|_{1}\right\} \leqq(1 / 8) 2^{-2 m} \text { if } \quad i=2,3 .
$$

Let $k: R \rightarrow R$ be the function defined by $k(e)=b-2^{-2 m} e^{2}$. Then $k^{\prime}(e)<-2^{-2 m}$ if $1 / 2<e<1$. Hence (4.7) yields

$$
m\left\{e \in R: 1 / 2<e<1 \text { and } M g_{i}\left(b-2^{-2 m} e^{2}\right)>(40) 2^{2 m}\left\|g_{i}\right\|_{1}\right\} \leqq 1 / 8
$$


if $i=2,3$. From (4.4) and (4.8) we conclude that there exists $e$ such that $1 / 2<e<1$ and (4.9) holds:

$$
\begin{aligned}
M g_{1}\left(2^{-m} e\right) & \leqq(40) 2^{m}\left\|g_{1}\right\|_{1}, \\
M g_{2}\left(b-2^{-2 m} e^{2}\right) & \leqq(40) 2^{2 m}\left\|g_{2}\right\|_{1}, \\
M g_{3}\left(b-2^{-2 m} e^{2}\right) & \leqq(40) 2^{2 m}\left\|g_{3}\right\|_{1}
\end{aligned}
$$

Now define $v, a^{\prime}, b^{\prime}$ as in the statement of the lemma using this particular $e$. If $0<r \leqq 2^{-m+1}$ then (4.2), (4.9), and (4.1) yield

$$
\begin{aligned}
I\left(|D v|^{2}, T\left(a^{\prime}, b^{\prime}, 2^{-m}, 2^{-2 m}, r\right)\right) \\
\quad=\left(e^{-1}\right) I\left(|D u|^{2}, T\left(a, b, 2^{-m} e, 2^{-2 m} e^{2}, r e\right)\right) \\
\quad \leqq\left(e^{-1}\right) I\left(|D u|^{2}, T\left(a, b, 2^{-m} e, 2^{-2 m}, r e\right)\right) \\
\quad \leqq\left(e^{-1}\right)(2 r e) M g_{1}\left(2^{-m} e\right) \\
\quad \leqq(80) 2^{m} r\left\|g_{1}\right\|_{1} \\
\quad=(80) 2^{m} r I\left(|D u|^{2}, K\left(a, b, 2^{-m+2}, 2^{-2 m}\right)\right) .
\end{aligned}
$$

If $0<s \leqq 2^{-2 m}$ then (4.6) and (4.9) yield

$$
\begin{aligned}
& I\left(|D v|^{2}, K\left(a^{\prime}, b^{\prime}-2^{-2 m}+s, 2^{-m+2}, s\right)\right) \\
& \quad=\left(e^{-1}\right) I\left(|D u|^{2}, K\left(a, b-2^{-2 m} e^{2}+s e^{2}, 2^{-m+2} e, s e^{2}\right)\right) \\
& \quad \leqq\left(e^{-1}\right) I\left(|D u|^{2}, K\left(a, b-2^{m-2} e^{2}+s e^{2}, 2^{-m+2}, s e^{2}\right)\right) \\
& \quad \leqq\left(e^{-1}\right)\left(2 s e^{2}\right) M g_{3}\left(b-2^{-2 m} e^{2}\right) \\
& \quad \leqq(80) 2^{2 m} s\left\|g_{3}\right\|_{1} \\
& \quad=(80) 2^{2 m} s I\left(|D u|^{2}, K\left(a, b, 2^{-m+2}, 2^{-2 m}\right)\right) .
\end{aligned}
$$

If $0<s \leqq 2^{-2 m}$ then (4.5) and (4.9) yield

$$
\begin{aligned}
& \int_{b^{\prime}-2^{-2 m}}^{b^{\prime}-2-2 m+s}|v(x, t)|^{2}\left(\left|x-a^{\prime}\right|+2^{-m}\right)^{-4} d x d t \\
& \quad=\left(e^{-3}\right)\left(\int_{b-2}^{b-2-2 m e^{2}} \int_{R^{3}}|u(x, t)|^{2}\left(\left|e^{-1}(x-a)\right|+2^{-m}\right)^{-4} d x d t\right) \\
& \quad \leqq\left(e^{-3}\right)\left(\int_{b-2}^{b-2-2 m e^{2}+s e^{2}} \int_{R^{3}}|u(x, t)|^{2}\left(|x-a|+2^{-m}\right)^{-4} d x d t\right) \\
& \quad \leqq\left(e^{-3}\right)\left(2 s e^{2}\right) M g_{2}\left(b-2^{-2 m} e^{2}\right) \leqq(160) 2^{2 m} s\left\|g_{2}\right\|_{1} \\
& =(160) 2^{2 m} S\left(\int_{b-2^{-2 m}}^{b} \int_{R^{3}}|u(x, t)|^{2}\left(|x-a|+2^{-m}\right)^{-4} d x d t\right) .
\end{aligned}
$$

The conclusion of the lemma follows from (4.10), (4.11), (4.12).

The purpose of Sects. $2-4$ is to prove the following theorem:

Theorem 4.2. For every positive number $H$ there exist positive constants $C_{5}(H)$ and $C_{6}(H)$, which depend only on $H$, such that the following is satisfied. Suppose we have the following conditions: $a \in R^{3}, b \in R^{+}, m$ is an integer, $b>2^{-2 m}, \Gamma \in R^{+}$, 
$u: R^{3} \times R^{+} \rightarrow R^{3}$ is a continuous function satisfying (2.1) and (2.2), the conditions

$$
\begin{array}{r}
I\left(|D u|^{2}, K\left(a, b, 2^{-m+2}, 2^{-2 m}\right)\right) \\
\int_{b-2^{-2 m}}^{b} \int_{R^{3}}|u(x, t)|^{2}\left(|x-a|+C_{5}(H) 2^{-m}\right)^{-4} d x d t \leqq C_{5}(H) 2^{m}, \\
\Gamma \leqq C_{5}(H) 2^{m}
\end{array}
$$

are satisfied, and inequality (3.1) holds whenever $c, d, h$ satisfy the properties $(c, d) \in K\left(a, b, 2^{-m}, 2^{-2 m}\right), 0<h \leqq 2^{-m}$, and $d>h^{2}$. Then we can conclude that (4.16) holds :

$$
|u(x, t)| \leqq C_{6}(H) 2^{m} \quad \text { if } \quad(x, t) \in K\left(a, b, 2^{-m-2}, 2^{-2 m-3}\right) .
$$

Proof. We set $C_{5}(H)=(160)^{-1} C_{3}(H)$ and $C_{6}(H)=(4) C_{4}(H)$ (see Lemma 3.1). We use Lemma 4.1 to find $e$ and define $v, a^{\prime}, b^{\prime}$. Then the hypotheses (4.13) and (4.14) and Lemma 4.1 yield

$$
\begin{aligned}
& I\left(|D v|^{2}, T\left(a^{\prime}, b^{\prime}, 2^{-m}, 2^{-2 m}, r\right)\right) \\
& \quad \leqq C_{3}(H) r \quad \text { if } \quad 0<r \leqq 2^{-m+1}, \\
& I\left(|D v|^{2}, K\left(a^{\prime}, b^{\prime}-2^{-2 m}+s, 2^{-m+2}, s\right)\right) \\
& \quad \leqq C_{3}(H) 2^{m} S \quad \text { if } \quad 0<s \leqq 2^{-2 m}, \\
& b^{\prime}-2-2 m+s \\
& \int_{b^{\prime}-2 m} \int_{R^{3}}|v(x, t)|^{2}\left(\left|x-a^{\prime}\right|+2^{-m}\right)^{-4} d x d t \\
& \leqq C_{3}(H) 2^{3 m} S \text { if } \quad 0<s \leqq 2^{-2 m} .
\end{aligned}
$$

Our objective is to show that the hypotheses of Lemma 3.1 hold when $a, b, \Gamma, u$ are replaced by $a^{\prime}, b^{\prime}, e \Gamma, v$. The above shows that we already have the analogue of (3.2)-(3.4). The analogue of (3.5) and $b^{\prime}>2^{-2 m}$ follow from $1 / 2<e<1$ and the hypotheses. We proceed to prove the analogue of (3.1). We assume $\left(c^{\prime}, d^{\prime}\right) \in K\left(a^{\prime}, b^{\prime}, 2^{-m}, 2^{-2 m}\right), 0<h^{\prime} \leqq 2^{-m}, d^{\prime}>\left(h^{\prime}\right)^{2}$. Setting $c=e c^{\prime}, d=e^{2} d^{\prime}, h=e h^{\prime}$ we obtain $(c, d) \in K\left(a, b, 2^{-m}, 2^{-2 m}\right)$ and $0<h \leqq 2^{-m}$ from $1 / 2<e<1$. We also conclude $d>h^{2}$. The hypotheses of the theorem yield (3.1) (as written), which can be expressed as

$$
\begin{aligned}
& H^{-1}\left|v\left(c^{\prime}, d^{\prime}\right)\right| \\
& \leqq \\
& \quad \int_{d^{\prime}-\left(h^{\prime}\right)^{2}}^{d^{\prime}} \int_{R^{3}}|v(y, s)|^{2}\left(\left|y-c^{\prime}\right|+\left(d^{\prime}-s\right)^{1 / 2}\right)^{-4} d y d s \\
& \quad+\int_{d^{\prime}-\left(h^{\prime}\right)^{2}}^{d^{\prime}} \int_{R^{3}}|v(y, s)|\left(\left|y-c^{\prime}\right|+h^{\prime}\right)^{-4}\left(h^{\prime}\right)^{-1} d y d s+e \Gamma .
\end{aligned}
$$

This is the analogue of (3.1). Lemma 3.1 yields $|v(x, t)| \leqq C_{4}(H) 2^{m+1}$ if $(x, t) \in K\left(a^{\prime}, b^{\prime}, 2^{-(m+1)}, 2^{-2 m}(3 / 4)\right)$. Combining this with $1 / 2<e<1$ we obtain (4.16). 


\section{Properties of Approximate Solutions}

Definition 5.1. We fix, once and for all, a $C^{\infty}$ function $\theta: R^{3} \rightarrow[0,1]$ such that $\theta(x)=0$ if $|x| \geqq 1, \theta(x)=1$ if $|x| \leqq 1 / 2$, and $\theta(x)=\theta(-x)$. We define $\theta^{\prime} \in C_{0}^{\infty}\left(R^{3}, R\right)$ by $\theta^{\prime}(x)=\theta(x) /\|\theta\|_{1}$ and for every $\varepsilon>0$ we define $\theta_{\varepsilon}^{\prime} \in \mathrm{C}_{0}^{\infty}\left(\mathrm{R}^{3}, \mathrm{R}\right)$ by $\theta_{\varepsilon}^{\prime}(x)=\varepsilon^{-3} \theta^{\prime}\left(\varepsilon^{-1} x\right)$. We have $\left\|\theta_{\varepsilon}^{\prime}\right\|_{1}=1$ and the estimates $\left\|\theta_{\varepsilon}^{\prime}\right\|_{\infty} \leqq C \varepsilon^{-3},\left\|D_{i} \theta_{\varepsilon}^{\prime}\right\|_{\infty} \leqq C \varepsilon^{-4},\left\|D_{i j} \theta_{\varepsilon}^{\prime}\right\|_{\infty}$ $\leqq C \varepsilon^{-5}$, and $\left\|D_{i j k} \theta_{\varepsilon}^{\prime}\right\|_{\infty} \leqq C \varepsilon^{-6}$.

For the remainder of this section we fix $0<\alpha<\varepsilon$ such that

$$
\left\|\Delta\left(\theta_{\varepsilon}^{\prime}\right)-\Delta\left(\theta_{\varepsilon}^{\prime} * \theta_{\alpha}^{\prime} * \theta_{\alpha}^{\prime}\right)\right\|_{2} \leqq 1
$$

This means, of course, that $\alpha$ is much smaller than $\varepsilon$ when $\varepsilon$ is small.

Definition 5.2. We set $\Phi=\theta_{\varepsilon}^{\prime}, \Omega=\theta_{\alpha}^{\prime}$, and $\Psi=\Phi * \Omega$. Observe that we have $\|\Psi\|_{1}=1$, $\Psi(x)=0$ if $|x| \geqq 2 \varepsilon,\|\Psi\|_{\infty} \leqq\|\Phi\|_{\infty}\|\Omega\|_{1} \leqq C \varepsilon^{-3}, \quad\left\|D_{i} \Psi\right\|_{\infty} \leqq\left\|D_{i} \Phi\right\|_{\infty}\|\Omega\|_{1} \leqq C \varepsilon^{-4}$, $\left\|D_{i j} \Psi\right\|_{\infty} \leqq C \varepsilon^{-5}$, and $\left\|D_{i j k} \Psi\right\|_{\infty} \leqq C \varepsilon^{-6}$. Let $X$ be the Hilbert space of all square integrable functions $f: R^{3} \rightarrow R^{3}$ with the inner product $(f, g)=\int f_{i}(x) g_{i}(x) d x$. Recall that $U$ is the open subset of $R^{3}$ given in Sect. 1 . We define $W$ to be the closed linear subspace of $X$ consisting of all $w$ such that (1) $w(x)=0$ for almost every $x \notin U,(2)$ $\int w_{i}(x) D_{i} g(x) d x=0$ for every $g \in C_{0}^{\infty}\left(R^{3}, R\right)$. The orthogonal projection of $X$ onto $W$ will be denoted by $P$. The function $S: W \rightarrow X$ is defined by

$$
S(w)_{i}=-\left(\left(w_{j} * \Psi\right) D_{j}\left(w_{i} * \Psi\right)\right) * \Psi+\Delta\left(w_{i} * \Omega * \Omega\right)
$$

Lemma 5.3. There exists a number $M<\infty$ (which depends on $\Phi$ and $\Omega$ ) such that

$$
\left\|P(S(w))-P\left(S\left(w^{\prime}\right)\right)\right\|_{2} \leqq M\left\|w-w^{\prime}\right\|_{2}\left(\|w\|_{2}+\left\|w^{\prime}\right\|_{2}+1\right) \quad \text { if } \quad w, w^{\prime} \in W
$$

Proof. Using Young's inequality and the Schwarz inequality we obtain

$$
\begin{aligned}
&\left\|S(w)_{i}-S\left(w^{\prime}\right)_{i}\right\|_{2} \\
& \leqq\left\|\left(\left(w_{j} * \Psi\right)\left(\left(w_{i}-w_{i}^{\prime}\right) * D_{j} \Psi\right)\right) * \Psi+\left(\left(\left(w_{j}-w_{j}^{\prime}\right) * \Psi\right)\left(w_{i}^{\prime} * D_{j} \Psi\right)\right) * \Psi\right\|_{2} \\
& \quad+\left\|\left(w_{i}-w_{i}^{\prime}\right) * \Delta(\Omega * \Omega)\right\|_{2} \\
& \leqq\left\|\left(w_{j} * \Psi\right)\left(\left(w_{i}-w_{i}^{\prime}\right) * D_{j} \Psi\right)\right\|_{2}\|\Psi\|_{1}+\left\|\left(\left(w_{j}-w_{j}^{\prime}\right) * \Psi\right)\left(w_{i}^{\prime} * D_{j} \Psi\right)\right\|_{2}\|\Psi\|_{1} \\
& \quad+\left\|w_{i}-w_{i}^{\prime}\right\|_{2}\|\Delta(\Omega * \Omega)\|_{1} \\
& \leqq\left\|w_{j} * \Psi\right\|_{\infty}\left\|\left(w_{i}-w_{i}^{\prime}\right) * D_{j} \Psi\right\|_{2}+\left\|\left(w_{j}-w_{j}^{\prime}\right) * \Psi\right\|_{2}\left\|w_{i}^{\prime} * D_{j} \Psi\right\|_{\infty} \\
& \quad+\left\|w_{i}-w_{i}^{\prime}\right\|_{2}\|\Delta(\Omega * \Omega)\|_{1} \\
& \leqq\left\|w_{j}\right\|_{2}\|\Psi\|_{2}\left\|w_{i}-w_{i}^{\prime}\right\|_{2}\left\|D_{j} \Psi\right\|_{1}+\left\|w_{j}-w_{j}^{\prime}\right\|_{2}\|\Psi\|_{1}\left\|w_{i}^{\prime}\right\|_{2}\left\|D_{j} \Psi\right\|_{2} \\
&+\left\|w_{i}-w_{i}^{\prime}\right\|_{2}\|\Delta(\Omega * \Omega)\|_{1} .
\end{aligned}
$$

Finally, we have $\left\|P\left(S(w)-S\left(w^{\prime}\right)\right)\right\|_{2} \leqq\left\|S(w)-S\left(w^{\prime}\right)\right\|_{2}$ because $P$ is an orthogonal projection. 
Lemma 5.4. If $w \in W$ then $(P(S(w)), w)=-\int|D(w * \Omega)(x)|^{2} d x$.

Proof. The definition of $W$, the symmetry of $\Psi$ and $\Omega$, and approximation by $C^{\infty}$ functions yields

$$
\begin{aligned}
& (P(S(w)), w)=(S(w), w) \\
& \quad=-\int\left(\left(\left(w_{j} * \Psi\right) D_{j}\left(w_{i} * \Psi\right)\right) * \Psi\right) w_{i}+\int\left(\Delta\left(w_{i} * \Omega * \Omega\right)\right) w_{i} \\
& \quad=-\int\left(\left(w_{j} * \Psi\right) D_{j}\left(w_{i} * \Psi\right)\right)\left(w_{i} * \Psi\right)+\int\left(\Delta\left(w_{i} * \Omega\right)\right)\left(w_{i} * \Omega\right) \\
& \quad=-(1 / 2)\left(\int\left(w_{j} * \Psi\right) D_{j}\left(|w * \Psi|^{2}\right)\right)-\int|D(w * \Omega)|^{2}=-\int|D(w * \Omega)|^{2} .
\end{aligned}
$$

Definition 5.5. If $f$ is a function from an open interval of $R$ into $X, s$ is an element of the interval, and $(f(s+h)-f(s)) / h$ converges in norm as $h$ approaches zero, then the limit is denoted by $D_{t} f(s)$.

Recall that $w^{0}$ is the initial condition given in Sect. 1.

Lemma 5.6. There exists a norm continuous function $w:[0, \infty) \rightarrow W$ such that $w(0)=w^{0}, D_{t} w$ exists and is a norm continuous function from $(0, \infty)$ into $W$,

$$
\begin{aligned}
& \left(D_{t} w\right)(s)=P(S(w(s))), \\
& \|w(s)\|_{2} \leqq\left\|w^{0}\right\|_{2} \quad \text { if } \quad s \geqq 0,
\end{aligned}
$$

and

$$
\int_{0}^{\infty} \int_{R^{3}}|D(w(s) * \Psi)(x)|^{2} d x d s \leqq(1 / 2)\left\|w^{0}\right\|_{2}^{2} .
$$

Proof. The result in Lemma 5.3 and the standard local existence proof for ordinary differential equations yield $\delta>0$ with the following property: If $s \in R, w^{\prime} \in W$, and $\left\|w^{\prime}\right\|_{2} \leqq\left\|w^{0}\right\|_{2}$ then (5.3) can be solved on the interval $[s, s+\delta]$ with initial condition $w^{\prime}$ at $s$. Since Lemma 5.4 yields $(d / d t)\|w(t)\|_{2}^{2} \leqq 0$ for any solution of (5.3), the local solutions can be pieced together into a global solution with initial condition $w^{0}$ at 0 that satisfies (5.4). From Lemma 5.4 we obtain

$$
\int_{0}^{\infty} \int_{R^{3}}|D(w(s) * \Omega)(x)|^{2} d x d s \leqq(1 / 2)\left\|w^{0}\right\|_{2}^{2}
$$

In addition, Young's inequality yields

$$
\begin{aligned}
\int_{R^{3}}|D(w(s) * \Psi)(x)|^{2} d x & =\int_{R^{3}}|D(w(s) * \Omega * \Phi)(x)|^{2} d x \\
& \leqq\left(\int_{R^{3}}|D(w(s) * \Omega)(x)|^{2} d x\right)\|\Phi\|_{1}^{2} .
\end{aligned}
$$

Now (5.5) follows from $\|\Phi\|_{1}=1$.

Lemma 5.7. If $f: R^{3} \sim\{0\} \rightarrow R$ is a $C^{\infty}$ function, if $i, j, k$ are elements of $\{1,2,3\}$, $M \geqq 0,|f(x)| \leqq M|x|^{-1},\left|D_{i j k} f(x)\right| \leqq M|x|^{-4}, g \in C_{0}^{\infty}\left(R^{3}, R\right), r>0$, and $g(x)=0$ whenever $|x| \geqq r$ then

$$
\begin{aligned}
|(f * g)(x)| & \leqq C M\left(\|g\|_{1}+r^{3}\|g\|_{\infty}\right)|x|^{-1} \\
\left|D_{i j k}(f * g)(x)\right| & \leqq C M\left(\|g\|_{1}+r^{6}\left\|D_{i j k} g\right\|_{\infty}\right)|x|^{-4}, \\
\left\|D_{i j k}(f * g)\right\|_{\infty} & \leqq C M\left(\|g\|_{1}+r^{6}\left\|D_{i j k} g\right\|_{\infty}\right) r^{-4}
\end{aligned}
$$


Proof. If $|x| \geqq 2 r$ then

$$
\begin{aligned}
|(f * g)(x)| & =\left|\int_{|x-y| \leqq|x| / 2} f(y) g(x-y) d y\right| \\
& \leqq M(|x| / 2)^{-1}\left(\int_{|x-y| \leqq|x| / 2}|g(x-y)| d y\right)=2 M|x|^{-1}\|g\|_{1} .
\end{aligned}
$$

If $|x| \geqq 2 r$ then a similar argument yields

$$
\left|D_{i j k}(f * g)(x)\right|=\left|\left(D_{i j k} f * g\right)(x)\right| \leqq 16 M|x|^{-4}\|g\|_{1} .
$$

If $|x|<2 r$ then

$$
\begin{aligned}
|(f * g)(x)| & =\left|\int_{|y| \leqq 3 r} f(y) g(x-y) d y\right| \\
& \leqq\left(\int_{|y| \leqq 3 r}|f(y)| d y\right)\|g\|_{\infty} \leqq C M r^{2}\|g\|_{\infty}=C M r^{-1}\left(r^{3}\|g\|_{\infty}\right) .
\end{aligned}
$$

Once again, if $|x|<2 r$ then the same argument yields

$$
\left|D_{i j k}(f * g)(x)\right|=\left|\left(f * D_{i j k} g\right)(x)\right| \leqq C M r^{2}\left\|D_{i j k} g\right\|_{\infty}=C M r^{-4}\left(r^{6}\left\|D_{i j k} g\right\|_{\infty}\right)
$$

The conclusion follows by combining these estimates.

Definition 5.8. The functions $J: R^{3} \sim\{0\} \rightarrow R$ and $Q_{t}: R^{3} \rightarrow R$ for $t>0$ are given by

$$
\begin{aligned}
J(x) & =-(4 \pi|x|)^{-1} \\
Q_{t}(x) & =(2 \sqrt{\pi})^{-3} t^{-3 / 2} \exp \left(-|x|^{2} /(4 t)\right)
\end{aligned}
$$

Lemma 5.9. If $t>0, R>2\left(t^{1 / 2}\right), \lambda(x)=\theta\left((2 R)^{-1} x\right), J^{\prime}(x)=\lambda(x) J(x)$, and $g(x)=\lambda(x) Q_{t}(x)$ then

$$
\left|D_{i j k}\left(J^{\prime} * g * \Psi * \Psi\right)(x)\right| \leqq C\left(|x|+t^{1 / 2}\right)^{-4} \text { for all } x \in R^{3} .
$$

Proof. We fix $i, j, k \in\{1,2,3\}$. The integer $n$ is defined by the condition $2^{-n} R \geqq t^{1 / 2}$ $>2^{-n-1} R$. From $R>2\left(t^{1 / 2}\right)$ we conclude $n \geqq 1$. For any integer $m$ satisfying $0 \leqq m \leqq n$ we set $\lambda_{m}(x)=\lambda\left(2^{m} x\right)$. We also define $g_{m}(x)=\left(\lambda_{m}-\lambda_{m+1}\right)(x) Q_{t}(x)$ for $0 \leqq m<n$, and $g_{n}(x)=\lambda_{n}(x) Q_{t}(x)$. We have the following properties:

$$
\begin{aligned}
& g(x)=\sum_{m=0}^{n} g_{m}(x), \quad g_{m}(x)=0 \quad \text { if } \quad|x| \geqq 2^{1-m} R, \quad \sum_{m=0}^{n}\left\|g_{m}\right\|_{1}=\|g\|_{1} \leqq 1, \\
& \sum_{m=0}^{n}\left(2^{1-m} R\right)^{3}\left\|g_{m}\right\|_{\infty} \leqq C, \quad \sum_{m=0}^{n}\left(2^{1-m} R\right)^{6}\left\|D_{i j k} g_{m}\right\|_{\infty} \leqq C .
\end{aligned}
$$


We also have $\left|J^{\prime}(x)\right| \leqq C|x|^{-1},\left|D_{i j k} J^{\prime}(x)\right| \leqq C|x|^{-4}$. Now we can use Lemma 5.7 to conclude

$$
\begin{aligned}
& \left|\left(J^{\prime} * g\right)(x)\right| \leqq \sum_{m=0}^{n}\left|\left(J^{\prime} * g_{m}\right)(x)\right| \\
& \quad \leqq \sum_{m=0}^{n} C\left(\left\|g_{m}\right\|_{1}+\left(2^{1-m} R\right)^{3}\left\|g_{m}\right\|_{\infty}\right)|x|^{-1} \leqq C|x|^{-1}, \\
& \left|D_{i j k}\left(J^{\prime} * g\right)(x)\right| \leqq \sum_{m=0}^{n}\left|D_{i j k}\left(J^{\prime} * g_{m}\right)(x)\right| \\
& \quad \leqq \sum_{m=0}^{n} C\left(\left\|g_{m}\right\|_{1}+\left(2^{1-m} R\right)^{6}\left\|D_{i j k} g_{m}\right\|_{\infty}\right)|x|^{-4} \leqq C|x|^{-4}, \\
& \left\|D_{i j k}\left(J^{\prime} * g\right)\right\|_{\infty} \leqq \sum_{m=0}^{n}\left\|D_{i j k}\left(J^{\prime} * g_{m}\right)\right\|_{\infty} \\
& \quad \leqq \sum_{m=0}^{n} C\left(\left\|g_{m}\right\|_{1}+\left(2^{1-m} R\right)^{6}\left\|D_{i j k} g_{m}\right\|_{\infty}\right)\left(2^{1-m} R\right)^{-4} \\
& \quad \leqq \sum_{m=0}^{n} C\left(\left\|g_{m}\right\|_{1}+\left(2^{1-m} R\right)^{6}\left\|D_{i j k} g_{m}\right\|_{\infty}\right)\left(t^{1 / 2}\right)^{-4} \leqq C\left(t^{1 / 2}\right)^{-4} .
\end{aligned}
$$

We also have

$$
\|\Psi * \Psi\|_{1}=\|\Psi\|_{1}\|\Psi\|_{1}=1
$$

and

$$
\left\|D_{i j k}(\Psi * \Psi)\right\|_{\infty} \leqq\left\|D_{i j k} \Psi\right\|_{\infty}\|\Psi\|_{1} \leqq C \varepsilon^{-6} .
$$

Hence (5.8), (5.9), the fact that $(\Psi * \Psi)(x)=0$ whenever $|x| \geqq 4 \varepsilon$, and Lemma 5.7 yield

$$
\left|D_{i j k}\left(J^{\prime} * g * \Psi * \Psi\right)(x)\right| \leqq C\left(\|\Psi * \Psi\|_{1}+(4 \varepsilon)^{6}\left\|D_{i j k}(\Psi * \Psi)\right\|_{\infty}\right)|x|^{-4} \leqq C|x|^{-4} .
$$

From (5.10) we obtain

$$
\begin{aligned}
\left\|D_{i j k}\left(J^{\prime} * g * \Psi * \Psi\right)\right\|_{\infty} & \leqq\left\|D_{i j k}\left(J^{\prime} * g\right)\right\|_{\infty}\|\Psi * \Psi\|_{1} \\
& =\left\|D_{i j k}\left(J^{\prime} * g\right)\right\|_{\infty} \leqq C\left(t^{1 / 2}\right)^{-4}
\end{aligned}
$$

Now (5.11) and (5.12) yield the conclusion of the lemma by considering separately the cases $|x|>t^{1 / 2}$ and $|x| \leqq t^{1 / 2}$.

Definition 5.10. The $i$ components of $w(s)$ and $\left(D_{t} w\right)(s)$ will be written $w_{i}(s)$ and $D_{t} w_{i}(s)$ (see Lemma 5.6). We will also use the notation $w_{i}^{\prime}(s)=w_{i}(s) * \Psi$ and $w^{\prime}(s)=w(s) * \Psi$.

Lemma 5.11. If the hypotheses of Lemma 5.9 are satisfied, $c \in U$,

$$
\left\{x \in R^{3}:|x-c| \leqq 4 R+2 \varepsilon\right\} \subset U,
$$


and $s>0$ then

$$
\begin{aligned}
& \left|\int_{R^{3}}\left[\left(D_{t} w_{i}^{\prime}(s)-\Delta\left(w_{i}^{\prime}(s)\right)\right)(x)\right]\left[\Delta\left(g * J^{\prime}\right)(x-c)\right] d x\right| \\
& \quad \leqq C\left(\int_{R^{3}}\left|\left(w^{\prime}(s)\right)(x)\right|^{2}\left(|x-c|+t^{1 / 2}\right)^{-4} d x\right)+\left\|w^{0}\right\|_{2}\left\|\Delta\left(g * J^{\prime}\right)\right\|_{1} .
\end{aligned}
$$

Proof. We fix $i \in\{1,2,3\}$ and define $f: R^{3} \rightarrow R^{3}$ by $f_{i}=g, f_{j}=0$ if $j \neq i$. We have

$$
\Delta\left(f * J^{\prime} * \Psi\right)=-\operatorname{curl}\left(\operatorname{curl}\left(f * J^{\prime} * \Psi\right)\right)+\operatorname{grad}\left(\operatorname{div}\left(f * J^{\prime} * \Psi\right)\right)
$$

Hence we can use $D_{t} w(s) \in W$, the fact that the function

$$
h(x)=\operatorname{curl}\left(\operatorname{curl}\left(f * J^{\prime} * \Psi\right)\right)(x-c)
$$

is an element of $W,(5.3),(5.2)$, and $w(s) \in W$ to conclude

$$
\begin{aligned}
\int\left[\left(D_{t} w_{i}^{\prime}(s)\right)(x)\right]\left[\Delta\left(g * J^{\prime}\right)(x-c)\right] d x \\
=\int\left[\left(D_{t} w_{n}^{\prime}(s)\right)(x)\right]\left[\Delta\left(f_{n} * J^{\prime}\right)(x-c)\right] d x \\
=\int\left[\left(D_{t} w_{n}(s)\right)(x)\right]\left[\Delta\left(f_{n} * J^{\prime} * \Psi\right)(x-c)\right] d x \\
=-\int\left[\left(D_{t} w_{n}(s)\right)(x)\right]\left[\operatorname{curl}\left(\operatorname{curl}\left(f * J^{\prime} * \Psi\right)\right)(x-c)\right]_{n} d x \\
=\int\left[\left(\left(w_{j}^{\prime}(s) D_{j}\left(w_{n}^{\prime}(s)\right)\right) * \Psi\right)(x)\right]\left[\operatorname{curl}\left(\operatorname{curl}\left(f * J^{\prime} * \Psi\right)\right)(x-c)\right]_{n} d x \\
\quad-\int\left[\Delta\left(w_{n}(s) * \Omega * \Omega\right)(x)\right]\left[\operatorname{curl}\left(\operatorname{curl}\left(f * J^{\prime} * \Psi\right)\right)(x-c)\right]_{n} d x \\
=-\int\left[\left(w_{j}^{\prime}(s)\right)(x)\right]\left[\left(w_{n}^{\prime}(s)\right)(x)\right]\left[D_{j}\left(\operatorname{curl}\left(\operatorname{curl}\left(f * J^{\prime} * \Psi * \Psi\right)\right)\right)(x-c)\right]_{n} d x \\
\quad+\int\left[\Delta\left(w_{n}(s) * \Omega * \Omega\right)(x)\right]\left[\Delta\left(f_{n} * J^{\prime} * \Psi\right)(x-c)\right] d x
\end{aligned}
$$

The Schwarz inequality, (5.4), Young's inequality, (5.1), and Definitions 5.1 and 5.2 yield

$$
\begin{aligned}
\mid \int[ & {\left[\left(w_{i}^{\prime}(s)\right)(x)\right]\left[\Delta\left(g * J^{\prime}\right)(x-c)\right] d x } \\
& \quad-\int\left[\Delta\left(w_{n}(s) * \Omega * \Omega\right)(x)\right]\left[\Delta\left(f_{n} * J^{\prime} * \Psi\right)(x-c)\right] d x \mid \\
= & \mid \int\left[\left(w_{i}(s) * \Delta \Psi\right)(x)\right]\left[\Delta\left(g * J^{\prime}\right)(x-c)\right] d x \\
& \quad-\int\left[\left(w_{i}(s) * \Delta(\Psi * \Omega * \Omega)\right)(x)\right]\left[\Delta\left(g * J^{\prime}\right)(x-c)\right] d x \mid \\
\leqq & \|w(s) *(\Delta(\Phi * \Omega)-\Delta(\Phi * \Omega * \Omega * \Omega))\|_{\infty}\left\|\Delta\left(g * J^{\prime}\right)\right\|_{1} \\
\leqq & \|w(s)\|_{2}\|(\Delta(\Phi)-\Delta(\Phi * \Omega * \Omega)) * \Omega\|_{2}\left\|\Delta\left(g * J^{\prime}\right)\right\|_{1} \\
\leqq & \left\|w^{0}\right\|_{2}\|\Delta(\Phi)-\Delta(\Phi * \Omega * \Omega)\|_{2}\|\Omega\|_{1}\left\|\Delta\left(g * J^{\prime}\right)\right\|_{1} \leqq\left\|w^{0}\right\|_{2}\left\|\Delta\left(g * J^{\prime}\right)\right\|_{1} .
\end{aligned}
$$

Finally, (5.13), (5.14), and Lemma 5.9 yield

$$
\begin{aligned}
& \left|\int\left[\left(D_{t} w_{i}^{\prime}(s)-\Delta\left(w_{i}^{\prime}(s)\right)\right)(x)\right]\left[\Delta\left(g * J^{\prime}\right)(x-c)\right] d x\right| \\
& \leq\left|\int\left[\left(w_{j}^{\prime}(s)\right)(x)\right]\left[\left(w_{n}^{\prime}(s)\right)(x)\right]\left[D_{j}\left(\operatorname{curl}\left(\operatorname{curl}\left(f_{*} J^{\prime} * \Psi * \Psi\right)\right)\right)(x-c)\right]_{n} d x\right| \\
& \quad+\left\|w^{0}\right\|_{2}\left\|\Delta\left(g * J^{\prime}\right)\right\|_{1} \\
& \quad<C\left(\int\left|\left(w^{\prime}(s)\right)(x)\right|^{2}\left(|x-c|+t^{1 / 2}\right)^{-4} d x\right)+\left\|w^{0}\right\|_{2}\left\|\Delta\left(g * J^{\prime}\right)\right\|_{1} .
\end{aligned}
$$


Theorem 5.12. There exists an absolute constant $C_{7}>0$ with the following property: If $c \in U, 0<h<R / 2, d>h^{2}$, and $\left\{x \in R^{3}:|x-c| \leqq 4 R+4 \varepsilon\right\} \subset U$ then

$$
\begin{aligned}
& C_{7}^{-1}\left|\left(w^{\prime}(d)\right)(c)\right| \\
& \leqq \\
& \int_{d-h^{2}}^{d} \int_{R^{3}}\left|\left(w^{\prime}(s)\right)(x)\right|^{2}\left(|x-c|+(d-s)^{1 / 2}\right)^{-4} d x d s \\
& \quad+\int_{d-h^{2}}^{d} \int_{R^{3}}\left|\left(w^{\prime}(s)\right)(x)\right|(|x-c|+h)^{-4} h^{-1} d x d s \\
& \quad+h^{2}\left\|w^{0}\right\|_{2}+h^{2}\left\|w^{0}\right\|_{2} R^{-7 / 2}+\left\|w^{0}\right\|_{2} R^{-3 / 2} .
\end{aligned}
$$

Proof. We fix $i \in\{1,2,3\}$, define $\lambda$ and $J^{\prime}$ as in Lemma 5.9, set $J^{\prime \prime}(x)=(1-\lambda(x)) J(x)$, and define the function $g$ and $f$ from $[0, d)$ into $C_{0}^{\infty}\left(R^{3}, R\right)$ by

$$
(g(s))(x)=\lambda(x) Q_{d-s}(x), \quad f(s)=\Delta\left(g(s) * J^{\prime}\right) .
$$

We have

$$
f(s)=\Delta(g(s) * J)-\Delta\left(g(s) * J^{\prime \prime}\right)=g(s)-g(s) * \Delta J^{\prime \prime} .
$$

Since $J^{\prime \prime}(x)=J(x)$ for $|x|>2 R$, we obtain $\Delta J^{\prime \prime}(x)=0$ for $|x|>2 R$. We also have $J^{\prime \prime}(x)=0$ for $|x|<R$. Combining this with $\|\lambda\|_{\infty} \leqq 1,\left\|D_{i} \lambda\right\|_{\infty} \leqq C R^{-1}$, and $\|\Delta \lambda\|_{\infty} \leqq C R^{-2}$ we obtain

$$
\left\|\Delta J^{\prime \prime}\right\|_{1} \leqq C, \quad\left\|\Delta J^{\prime \prime}\right\|_{2} \leqq C R^{-3 / 2} .
$$

From (5.15) and (5.16) we obtain

$$
\|f(s)\|_{1} \leqq\|g(s)\|_{1}+\|g(s)\|_{1}\left\|\Delta J^{\prime \prime}\right\|_{1} \leqq C .
$$

If we set $Y(x, s)=Q_{d-s}(x)$ for $s<d$ then we obtain $D_{t} Y+\Delta Y=0$. Hence we conclude

$$
\left(D_{t} g(s)+\Delta(g(s))\right)(x)=\Delta \lambda(x) Q_{d-s}(x)+2\left(D_{i} \lambda(x) D_{i} Q_{d-s}(x)\right)
$$

This shows

$$
\left(D_{t} g(s)+\Delta(g(s))\right)(x)=0 \text { if }|x|<R \text { or }|x|>2 R .
$$

We also have the estimates $\left|Q_{d-s}(x)\right| \leqq C|x|^{-3},\left|D_{i} Q_{d-s}(x)\right| \leqq C|x|^{-4}$. If $|x|>R$ then (5.18) yields

$$
\left|\left(D_{t} g(s)+\Delta(g(s))\right)(x)\right| \leqq C R^{-2}|x|^{-3}+C R^{-1}|x|^{-4} \leqq C R^{-5} \quad \text { if } \quad|x|>R .
$$

Now (5.19) and (5.20) yield $\left\|D_{t} g(s)+\Delta(g(s))\right\|_{2} \leqq C R^{-7 / 2}$.

Combining this with (5.15) and (5.16) we obtain

$$
\left\|D_{t} f(s)+\Delta(f(s))\right\|_{2} \leqq C R^{-7 / 2}+\left\|D_{t} g(s)+\Delta(g(s))\right\|_{2}\left\|\Delta J^{\prime \prime}\right\|_{1} \leqq C R^{-7 / 2} .
$$

From Definition 5.10 and (5.4) we obtain

$$
\left\|w^{\prime}(s)\right\|_{2} \leqq\|w(s)\|_{2}\|\Psi\|_{1} \leqq\|w(s)\|_{2} \leqq\left\|w^{0}\right\|_{2}
$$


Now suppose $d-h^{2} \leqq s^{\prime} \leqq d-h^{2} / 2<s^{\prime \prime}<d$. From Lemmas 5.6 and 5.11 , the Schwarz inequality, (5.21), (5.17), and (5.22) we obtain

$$
\begin{aligned}
& \mid \int_{R^{3}}\left[\left(w_{i}^{\prime}\left(s^{\prime \prime}\right)\right)(x)\right]\left[\left(f\left(s^{\prime \prime}\right)\right)(x-c)\right] d x \\
& \quad-\int_{R^{3}}\left[\left(w_{i}^{\prime}\left(s^{\prime}\right)\right)(x)\right]\left[\left(f\left(s^{\prime}\right)\right)(x-c)\right] d x \mid \\
&=\mid \int_{s^{\prime}}^{s^{\prime \prime}} \int_{R^{3}}\left[\left(D_{t} w_{i}^{\prime}(s)\right)(x)\right][(f(s))(x-c)] d x d s \\
& \quad+\int_{s^{\prime}}^{s_{R^{3}}}\left[\left(w_{i}^{\prime}(s)\right)(x)\right]\left[\left(D_{t} f(s)\right)(x-c)\right] d x d s \mid \\
& \leqq \mid \int_{s^{\prime}}^{s^{\prime \prime}} \int_{R^{3}}\left[\left(D_{t} w_{i}^{\prime}(s)\right)(x)\right][(f(s))(x-c)] d x d s \\
&-\int_{s^{\prime}}^{s^{\prime \prime}} \int_{R^{3}}\left[\left(w_{i}^{\prime}(s)\right)(x)\right][\Delta(f(s))(x-c)] d x d s \mid \\
&+\left|\int_{s^{\prime}}^{s^{\prime \prime}} \int_{R^{3}}\left[\left(w_{i}^{\prime}(s)\right)(x)\right]\left[\left(D_{t} f(s)+\Delta(f(s))\right)(x-c)\right] d x d s\right| \\
& \leqq C\left(\int_{s^{\prime}}^{s^{\prime \prime}} \int_{R^{3}}\left|\left(w^{\prime}(s)\right)(x)\right|^{2}\left(|x-c|+(d-s)^{1 / 2}\right)^{-4} d x d s\right) \\
&+\int_{s^{\prime}}^{s^{\prime \prime}}\left\|w^{0}\right\|\left\|_{2}\right\| f(s) \|_{1} d s+C\left(\int_{s^{\prime}}\left\|w^{\prime}(s)\right\|_{2} R^{-7 / 2} d s\right) \\
& \leqq C\left(\int_{s^{\prime}}^{s^{\prime \prime}} \int_{R^{3}}\left|\left(w^{\prime}(s)\right)(x)\right|^{2}\left(|x-c|+(d-s)^{1 / 2}\right)^{-4} d x d s\right) \\
&+C\left(s^{\prime \prime}-s^{\prime}\right)\left\|w^{0}\right\|\left\|_{2}+C\left(s^{\prime \prime}-s^{\prime}\right)\right\| w^{0} \|{ }_{2} R^{-7 / 2} .
\end{aligned}
$$

In addition, (5.15), (5.22), and (5.16) yield

$$
\begin{aligned}
& \mid \int_{R^{3}}\left[\left(w_{i}^{\prime}(s)\right)(x)\right][(f(s))(x-c)] d x \\
& -\int_{R^{3}}\left[\left(w_{i}^{\prime}(s)\right)(x)\right][(g(s))(x-c)] d x \\
& \leqq\left\|w^{\prime}(s)\right\|_{2}\left\|g(s) * \Delta J^{\prime \prime}\right\|_{2} \leqq\left\|w^{0}\right\|_{2}\|g(s)\|_{1}\left\|\Delta J^{\prime \prime}\right\|_{2} \leqq C\left\|w^{0}\right\|_{2} R^{-3 / 2}
\end{aligned}
$$

when $s=s^{\prime}$ or $s=s^{\prime \prime}$. From (5.23), (5.24), and the properties of $s^{\prime}, s^{\prime \prime}$ we get

$$
\begin{aligned}
& \mid \int_{R^{3}}\left[\left(w_{i}^{\prime}\left(s^{\prime \prime}\right)\right)(x)\right]\left[\left(g\left(s^{\prime \prime}\right)\right)(x-c)\right] d x \\
& \quad-\int_{R^{3}}\left[\left(w_{i}^{\prime}\left(s^{\prime}\right)\right)(x)\right]\left[\left(g\left(s^{\prime}\right)\right)(x-c)\right] d x \mid \\
& \leqq C\left(\int_{d-h^{2}}^{d} \int_{R^{3}}\left|\left(w^{\prime}(s)\right)(x)\right|^{2}\left(|x-c|+(d-s)^{1 / 2}\right)^{-4} d x d s\right) \\
&+C h^{2}\left\|w^{0}\right\|_{2}+C h^{2}\left\|w^{0}\right\|_{2} R^{-7 / 2}+C\left\|w^{0}\right\|_{2} R^{-3 / 2} .
\end{aligned}
$$


From Lemma 5.6 we obtain that the function $u(x, s)=\left(w^{\prime}(s)\right)(x)$ is bounded and continuous. This implies

$$
\lim _{s^{\prime \prime} \rightarrow d} \int_{R^{3}}\left[\left(w_{i}^{\prime}\left(s^{\prime \prime}\right)\right)(x)\right]\left[\left(g\left(s^{\prime \prime}\right)\right)(x-c)\right] d x=\left(w_{i}^{\prime}(d)\right)(c) .
$$

Since $d-h^{2} \leqq s^{\prime} \leqq d-h^{2} / 2$ we have

$$
\left|\left(g\left(s^{\prime}\right)\right)(x-c)\right| \leqq\left|Q_{d-s^{\prime}}(x-c)\right| \leqq C(|x-c|+h)^{-4} h .
$$

Combining (5.25)-(5.27) we obtain

$$
\begin{aligned}
\left|\left(w^{\prime}(d)\right)(c)\right| \leqq & C\left(\int_{d-h^{2}}^{d} \int_{R^{3}}\left|\left(w^{\prime}(s)\right)(x)\right|^{2}\left(|x-c|+(d-s)^{1 / 2}\right)^{-4} d x d s\right) \\
& +C\left(\int_{R^{3}}\left|\left(w^{\prime}\left(s^{\prime}\right)\right)(x)\right|(|x-c|+h)^{-4} h d x\right) \\
& +C h^{2}\left\|w^{0}\right\|_{2}+C h^{2}\left\|w^{0}\right\|_{2} R^{-7 / 2}+C\left\|w^{0}\right\|_{2} R^{-3 / 2}
\end{aligned}
$$

for $d-h^{2} \leqq s^{\prime} \leqq d-h^{2} / 2$. The conclusion follows by averaging (5.28) over $s^{\prime}$.

Lemma 5.13. If $s>0, f \in C_{0}^{\infty}\left(R^{3}, R\right)$, the distance between $\operatorname{spt}(f)$ and the complement of $U$ exceeds $2 \varepsilon$, $i \in\{1,2,3\}$, the function $g: R^{3} \rightarrow R^{3}$ is defined by $g_{i}=f, g_{j}=0$ whenever $j \neq i$, and $z:[0, \infty) \rightarrow X$ is defined by $z(s)=\operatorname{curl}\left(w^{\prime}(s)\right)$, then

$$
\begin{aligned}
& \int\left[\left(D_{t} z_{i}(s)\right)(x)\right][f(x)] d x \\
& =\int\left[\left(w_{j}^{\prime}(s)\right)(x)\right]\left[\left(z_{i}(s)\right)(x)\right]\left[D_{j}(f * \Psi * \Psi)(x)\right] d x \\
& \quad-\int\left[\left(z_{j}(s)\right)(x)\right]\left[\left(w_{i}^{\prime}(s)\right)(x)\right]\left[D_{j}(f * \Psi * \Psi)(x)\right] d x \\
& \quad+\int\left[\left(z_{i}(s)\right)(x)\right][\Delta f(x)] d x \\
& \quad+\int\left[\left(w_{n}(s) *(\Delta(\Psi * \Omega * \Omega)-\Delta \Psi)\right)(x)\right][\operatorname{curl}(g)(x)]_{n} d x .
\end{aligned}
$$

Proof. We fix $i \in\{1,2,3\}$. The fact $w(s) \in W \operatorname{implies} \operatorname{div}\left(w^{\prime}(s)\right)=0$. Hence we obtain

$$
\operatorname{curl}\left(w_{j}^{\prime}(s) D_{j}\left(w^{\prime}(s)\right)\right)=w_{j}^{\prime}(s) D_{j}(z(s))-z_{j}(s) D_{j}\left(w^{\prime}(s)\right) .
$$

Hence the property $\operatorname{curl}(g) * \Psi \in W$, Lemma 5.6, and the properties $\operatorname{div}\left(w^{\prime}(s)\right)=0$, $\operatorname{div}(z(s))=0$ yield

$$
\begin{aligned}
\int[ & \left.\left(D_{t} z_{i}(s)\right)(x)\right][f(x)] d x=\int\left[\left(D_{t} z_{n}(s)\right)(x)\right]\left[g_{n}(x)\right] d x \\
= & \int\left[\left(D_{t} w_{n}^{\prime}(s)\right)(x)\right][\operatorname{curl}(g)(x)]_{n} d x \\
= & \int\left[\left(D_{t} w_{n}(s)\right)(x)\right][(\operatorname{curl}(g) * \Psi)(x)]_{n} d x \\
= & -\int\left[\left(\left(w_{j}^{\prime}(s) D_{j}\left(w_{n}^{\prime}(s)\right)\right) * \Psi\right)(x)\right][(\operatorname{curl}(g) * \Psi)(x)]_{n} d x \\
& +\int\left[\Delta\left(w_{n}(s) * \Omega * \Omega\right)(x)\right][(\operatorname{curl}(g) * \Psi)(x)]_{n} d x \\
= & -\int\left[\left(w_{j}^{\prime}(s) D_{j}\left(z_{n}(s)\right)-z_{j}(s) D_{j}\left(w_{n}^{\prime}(s)\right)\right)(x)\right]\left[\left(g_{n} * \Psi * \Psi\right)(x)\right] d x \\
& +\int\left[\Delta\left(w_{n}^{\prime}(s)\right)(x)\right][\operatorname{curl}(g)(x)]_{n} d x \\
& +\int\left[\left(w_{n}(s) *(\Delta(\Psi * \Omega * \Omega)-\Delta \Psi)\right)(x)\right][\operatorname{curl}(g)(x)]_{n} d x \\
= & \int\left[\left(w_{j}^{\prime}(s) z_{n}(s)-z_{j}(s) w_{n}^{\prime}(s)\right)(x)\right]\left[D_{j}\left(g_{n} * \Psi * \Psi\right)(x)\right] d x \\
& +\int\left[\left(z_{n}(s)\right)(x)\right]\left[\Delta g_{n}(x)\right] d x \\
& +\int\left[\left(w_{n}(s) *(\Delta(\Psi * \Omega * \Omega)-\Delta \Psi)\right)(x)\right][\operatorname{curl}(g)(x)]_{n} d x .
\end{aligned}
$$


The conclusion of the lemma now follows.

Definition 5.14. The functions $u$ and $z$ from $R^{3} \times[0, \infty)$ into $R^{3}$ are defined by $u(x, s)=\left(w^{\prime}(s)\right)(x)$ and $z(x, s)=\left(\operatorname{curl}\left(w^{\prime}(s)\right)\right)(x)$.

Note that

$$
|u(x, s)| \leqq\|w(s)\|_{2}\|\Psi\|_{2} \leqq\left\|w^{0}\right\|_{2}\|\Psi\|_{2}
$$

and

$$
|D u(x, s)| \leqq\|w(s)\|_{2}\|D \Psi\|_{2} \leqq\left\|w^{0}\right\|_{2}\|D \Psi\|_{2}
$$

(see Lemma 5.6). Hence $u$ and $z$ are bounded functions.

Lemma 5.15. If $a \in U, b \in R$, and $h>0$ such that

$$
b>h^{2}, \quad\left\{x \in R^{3}:|x-a| \leqq h\right\} \subset U,
$$

and $\varepsilon<h / 64$ then there exist integrable functions

$$
\begin{aligned}
& F: R^{3} \times(-\infty, 0) \rightarrow R, \\
& G: R^{3} \times(-\infty, 0) \rightarrow R^{3},
\end{aligned}
$$

and

$$
H_{i}: R^{3} \times(-\infty, 0) \rightarrow R^{3}
$$

for $i \in\{1,2,3\}$ such that

(a) if either $|x| \geqq h / 8$ or $s \leqq-h^{2} / 8$ then $F(x, s)=0$ and $G(x, s)=H_{i}(x, s)=0$,

(b) $\|F\|_{1} \leqq C,\|F\|_{6 / 5} \leqq C h^{-5 / 6},\|G\|_{1} \leqq C h,\|G\|_{6 / 5} \leqq C h^{1 / 6},\left\|H_{i}\right\|_{1} \leqq C h$,

(c) if $c \in R^{3},|c-a| \leqq 7 h / 8$, and $b-7 h^{2} / 8 \leqq d \leqq b$ then

$$
\begin{aligned}
& z_{i}(c, d)=\int_{0}^{d} \int_{R^{3}}\left[u_{j}(x, s) z_{i}(x, s)-z_{j}(x, s) u_{i}(x, s)\right] G_{j}(x-c, s-d) d x d s \\
& \quad+\int_{0}^{d} \int_{R^{3}} z_{i}(x, s) F(x-c, s-d) d x d s \\
& \quad+\int_{0}^{d} \int_{R^{3}}\left[\left(w_{n}(s) *(\Delta(\Psi * \Omega * \Omega)-\Delta \Psi)\right)(x)\right]\left[H_{i}(x-c, s-d)\right]_{n} d x d s .
\end{aligned}
$$

Proof. We can find a $C^{\infty}$ function $\beta: R \rightarrow[0,1]$ such that $\beta(s)=0$ if

$$
s \leqq-h^{2} / 8, \quad \beta(s)=1 \quad \text { if } \quad s \geqq-h^{2} / 16,
$$

and $\left\|D_{t} \beta\right\|_{\infty} \leqq 32 h^{-2}$. We also define

$$
\eta: R^{3} \rightarrow[0,1] \text { by } \eta(x)=\theta\left(16 h^{-1} x\right)
$$

(see Definition 5.1). We fix $i \in\{1,2,3\}$ and define the functions

$$
f: R^{3} \times(-\infty, 0) \rightarrow R \text { and } g: R^{3} \times(-\infty, 0) \rightarrow R^{3}
$$

as follows:

$$
f(x, s)=\beta(s) \eta(x) Q_{-s}(x), \quad g_{i}(x, s)=f(x, s),
$$


and

$$
g_{j}(x, s)=0 \quad \text { if } \quad j \neq i .
$$

We set

$$
F=D_{t} f+\Delta f, \quad G_{j}=D_{j} f * \Psi * \Psi, \quad \text { and } \quad H_{i}=\operatorname{curl}(g) .
$$

If $c$ and $d$ are as in part (c) and $d-h^{2} / 16 \leqq d^{\prime}<d$ then Lemma 5.13 yields

$$
\begin{aligned}
& \int_{R^{3}} z_{i}\left(x, d^{\prime}\right) \eta(x-c) Q_{d-d^{\prime}}(x-c) d x=\int_{R^{3}} z_{i}\left(x, d^{\prime}\right) f\left(x-c, d^{\prime}-d\right) d x \\
& =\int_{0}^{d^{\prime}} \int_{R^{3}} D_{t} z_{i}(x, s) f(x-c, s-d) d x d s \\
& \quad+\int_{0}^{d^{\prime}} \int_{R^{3}} z_{i}(x, s) D_{t} f(x-c, s-d) d x d s \\
& =\int_{0}^{d^{\prime}} \int_{R^{3}}\left[u_{j}(x, s) z_{i}(x, s)-z_{j}(x, s) u_{i}(x, s)\right] G_{j}(x-c, s-d) d x d s \\
& \quad+\int_{0}^{d^{\prime}} \int_{R^{3}} z_{i}(x, s) F(x-c, s-d) d x d s \\
& \quad+\int_{0}^{d^{\prime}} \int_{R^{3}}\left[\left(w_{n}(s) *(\Delta(\Psi * \Omega * \Omega)-\Delta \Psi)\right)(x)\right]\left[H_{i}(x-c, s-d)\right]_{n} d x d s .
\end{aligned}
$$

Part (a) follows from $\varepsilon<h / 64$, Definition 5.1, and Definition 5.2. We have $F(x, s)=0$ if $|x| \leqq h / 32$ and $-h^{2} / 16 \leqq s<0$. This yields the estimates on $F$ in (b). We also have

$$
\left\|G_{j}\right\|_{p} \leqq\left\|D_{j} f\right\|_{p}\|\Psi * \Psi\|_{1}=\left\|D_{j} f\right\|_{p}\|\Psi\|_{1}\|\Psi\|_{1}=\left\|D_{j} f\right\|_{p}
$$

for $p=1$ and $p=6 / 5$. This and the definition of $f$ yield the rest of (b). Since $z$ is bounded and continuous (see Lemma 5.6), the left hand side of (5.29) converges to $z_{i}(c, d)$ as $d^{\prime} \rightarrow d$. Since $u, z$, and $w(s) *(\Delta(\Psi * \Omega * \Omega)-\Delta \Psi)$ are bounded and $G, F, H_{i}$ are integrable, we conclude that the integrals in (c) exist and that the right side of (5.29) converges to the right hand side of (c) as $d^{\prime} \rightarrow d$.

Theorem 5.16. If $a \in U, b \in R, h>0, b>h^{2},\left\{x \in R^{3}:|x-a| \leqq h\right\} \subset U, \varepsilon<h / 64$,

$$
K_{m}=\left\{(x, s) \in R^{3} \times R:|x-a| \leqq(4+m) h / 8, b-(4+m) h^{2} / 8 \leqq s \leqq b\right\},
$$

$M=\max \left\{|u(x, s)|:(x, s) \in K_{4}\right\}$, and $M^{\prime}=\int_{K_{4}}|D u|^{2}$ then there exist a function $\gamma:[0, \infty) \rightarrow[0, \infty)$ and a number $A<\infty$ such that

(a) $\gamma$ and $A$ depend only on $h, M, M^{\prime}$, and $\left\|w^{0}\right\|_{2}$,

(b) $\gamma(0)=0$ and $\lim _{\delta \rightarrow 0} \gamma(\delta)=0$,

(c) $|z(c, d)| \leqq A$ if $(c, d) \in K_{1}$,

(d) $\left|z(c, d)-z\left(c^{\prime}, d^{\prime}\right)\right| \leqq \gamma\left(\left|c-c^{\prime}\right|+\left|d-d^{\prime}\right|\right)$ if $(c, d)$ and $\left(c^{\prime}, d^{\prime}\right)$ are elements of $K_{0}$. 
Proof. If $(c, d) \in K_{3}$ we define (see Lemma 5.15)

$$
\begin{aligned}
z_{i}^{\prime}(c, d)= & \int_{0}^{d} \int_{R^{3}}\left[u_{j}(x, s) z_{i}(x, s)-z_{j}(x, s) u_{i}(x, s)\right] G_{j}(x-c, s-d) d x d s \\
& +\int_{0}^{d} \int_{R^{3}} z_{i}(x, s) F(x-c, s-d) d x d s, \\
z_{i}^{\prime \prime}(c, d)= & \int_{0}^{d} \int_{R^{3}}\left[\left(w_{n}(s) *(\Delta(\Psi * \Omega * \Omega)-\Delta \Psi)\right)(x)\right]\left[H_{i}(x-c, s-d)\right]_{n} d x d s .
\end{aligned}
$$

We have $z=z^{\prime}+z^{\prime \prime}$. Using Lemma 5.6, Definition 5.1, Definition 5.2, Lemma 5.15, and (5.1) we obtain

$$
\begin{aligned}
\left|z_{i}^{\prime \prime}(c, d)\right| & \leqq \int_{0}^{d}\left(\|w(s)\|_{2}\|\Delta(\Psi * \Omega * \Omega)-\Delta \Psi\|_{2}\right)\left(\int_{R^{3}}\left|H_{i}(x-c, s-d)\right| d x\right) d s \\
& \leqq C\left\|w^{0}\right\|_{2}\|(\Delta(\Phi * \Omega * \Omega)-\Delta \Phi) * \Omega\|_{2} h \\
& \leqq C\left\|w^{0}\right\|_{2}\|\Delta(\Phi * \Omega * \Omega)-\Delta \Phi\|_{2}\|\Omega\|_{1} h \leqq C\left\|w^{0}\right\|_{2} h .
\end{aligned}
$$

Using Young's inequality $\|f * g\|_{3} \leqq\|f\|_{2}\|g\|_{6 / 5}$ (see $[8$, p. 271]) and Lemma 5.15 yields

$$
\left(\int_{K_{3}}\left|z^{\prime}\right|^{3}\right)^{1 / 3} \leqq C\left(\int_{K_{4}}(|u \| z|)^{2}\right)^{1 / 2}\|G\|_{6 / 5}+C\left(\int_{K_{4}}|z|^{2}\right)^{1 / 2}\|F\|_{6 / 5}
$$

Since (5.31) yields $\left(\int_{K_{3}}\left|z^{\prime \prime}\right|^{3}\right)^{1 / 3} \leqq C\left\|w^{0}\right\|_{2} h^{8 / 3}$, we can use Lemma 5.15 and the above to obtain

$$
\begin{aligned}
\left(\int_{K_{3}}|z|^{3}\right)^{1 / 3} & \leqq C\left(\int_{K_{4}}(|u \| z|)^{2}\right)^{1 / 2} h^{1 / 6}+C\left(\int_{K_{4}}|z|^{2}\right)^{1 / 2} h^{-5 / 6}+C\left\|w^{0}\right\|_{2} h^{8 / 3} \\
& \leqq C\left(M+h^{-1}\right)\left(\int_{K_{4}}|z|^{2}\right)^{1 / 2} h^{1 / 6}+C\left\|w^{0}\right\|_{2} h^{8 / 3} .
\end{aligned}
$$

Once again we can use Young's inequality $\|f * g\|_{6} \leqq\|f\|_{3}\|g\|_{6 / 5}$ and Lemma 5.15 to obtain

$$
\left(\int_{K_{2}}\left|z^{\prime}\right|^{6}\right)^{1 / 6} \leqq C\left(\int_{K_{3}}(|u \| z|)^{3}\right)^{1 / 3}\|G\|_{6 / 5}+C\left(\int_{K_{3}}|z|^{3}\right)^{1 / 3}\|F\|_{6 / 5}
$$

From (5.31) we obtain $\left(\int_{K_{2}}\left|z^{\prime \prime}\right|^{6}\right)^{1 / 6} \leqq C\left\|w^{0}\right\|_{2} h^{11 / 6}$. Hence Lemma 5.15 and the above yield

$$
\begin{aligned}
\left(\int_{K_{2}}|z|^{6}\right)^{1 / 6} & \leqq C\left(\int_{K_{3}}(|u \| z|)^{3}\right)^{1 / 3} h^{1 / 6}+C\left(\int_{K_{3}}|z|^{3}\right)^{1 / 3} h^{-5 / 6}+C\left\|w^{0}\right\|_{2} h^{11 / 6} \\
& \leqq C\left(M+h^{-1}\right)\left(\int_{K_{3}}|z|^{3}\right)^{1 / 3} h^{1 / 6}+C\left\|w^{0}\right\|_{2} h^{11 / 6} .
\end{aligned}
$$


If $(c, d) \in K_{1}$ then Hölder's inequality, Lemma 5.15, and (5.31) yield

$$
\begin{aligned}
|z(c, d)| & \leqq\left|z^{\prime}(c, d)\right|+\left|z^{\prime \prime}(c, d)\right| \\
& \leqq C\left(\int_{K_{2}}(|u||z|)^{6}\right)^{1 / 6}\|G\|_{6 / 5}+C\left(\int_{K_{2}}|z|^{6}\right)^{1 / 6}\|F\|_{6 / 5}+C\left\|w^{0}\right\|_{2} h \\
& \leqq C\left(M+h^{-1}\right)\left(\int_{K_{2}}|z|^{6}\right)^{1 / 6} h^{1 / 6}+C\left\|w^{0}\right\|_{2} h .
\end{aligned}
$$

Combining (5.32)-(5.34), and the estimates $\left(\int_{K_{4}}|z|^{2}\right)^{1 / 2} \leqq C\left(\int_{K_{4}}|D u|^{2}\right)^{1 / 2}=C\left(M^{\prime}\right)^{1 / 2}$ we obtain that $|z|$ is bounded on $K_{1}$ by a number that depends only on $h, M, M^{\prime}$, and $\left\|w^{0}\right\|_{2}$. We conclude from this and from the argument in (5.31) that the functions

$$
\left|u_{j}(x, s) z_{i}(x, s)\right|,\left|z_{i}(x, s)\right| \text {, and }\left|\left(w_{n}(s) *(\Delta(\Psi * \Omega * \Omega)-\Delta \Psi)\right)(x)\right|
$$

are bounded on $K_{1}$ by a number that depends only on $h, M, M^{\prime}$, and $\left\|w^{0}\right\|_{2}$. The rest follows from Lemma 5.15 and the definitions of $G_{j}, F$, and $H_{i}$.

Lemma 5.17. There exist absolute constants $C_{8}$ and $C_{9}$ such that

$$
\int_{0}^{\infty} \int_{R^{3}}|u(x, t)|^{10 / 3} d x d t \leqq C_{8}\left\|w^{0}\right\|_{2}^{10 / 3}
$$

and

$$
\begin{aligned}
& \int_{b-2 m}^{b} \int_{R^{3}}|u(x, t)|^{2}\left(|x-a|+2^{-m}\right)^{-4} d x d t \\
& \leqq C_{9}\left(\int_{b-2-2 m}^{b} \int_{R^{3}}|u(x, t)|^{10 / 3}\left(|x-a|+2^{-m}\right)^{-4} d x d t\right)^{3 / 5} 2^{-2 m / 5}
\end{aligned}
$$

whenever $b>2^{-2 m}$ and $a \in R^{3}$.

Proof. Using Hölder's inequality, the first inequality in Line 9, p. 127 of [8], Definition 5.10, Definition 5.14, Young's inequality, and Lemma 5.6 we obtain

$$
\begin{aligned}
\int_{0}^{\infty} & \int_{R^{3}}|u(x, t)|^{10 / 3} d x d t \\
& =\int_{0}^{\infty} \int_{R^{3}}|u(x, t)|^{2}|u(x, t)|^{4 / 3} d x d t \\
& \leqq \int_{0}^{\infty}\left(\int_{R^{3}}|u(x, t)|^{6} d x\right)^{1 / 3}\left(\int_{R^{3}}|u(x, t)|^{2} d x\right)^{2 / 3} d t \\
& \leqq \int_{0}^{\infty} C\left(\int_{R^{3}}|D u(x, t)|^{2} d x\right)\left(\int_{R^{3}}|u(x, t)|^{2} d x\right)^{2 / 3} d t \\
& \int_{0}^{\infty} C\left(\int_{R^{3}}|D u(x, t)|^{2} d x\right)\left(\int_{R^{3}}|(w(t))(x)|^{2} d x\right)^{2 / 3}\|\Psi\|_{1}^{4 / 3} d t \\
& \leqq
\end{aligned}
$$


If $b>2^{-2 m}$ and $a \in R^{3}$ then Hölder's inequality yields

$$
\begin{aligned}
& \int_{b-2^{-2 m}}^{b} \int_{R^{3}}|u(x, t)|^{2}\left(|x-a|+2^{-m}\right)^{-4} d x d t \\
& =\int_{b-2^{-2 m}}^{b}\left(|u(x, t)|^{2}\left(|x-a|+2^{-m}\right)^{-12 / 5}\right)\left(|x-a|+2^{-m}\right)^{-8 / 5} d x d t \\
& \leqq \\
& \quad\left(\int_{b-2^{-2 m}}^{b} \int_{R^{3}}|u(x, t)|^{10 / 3}\left(|x-a|+2^{-m}\right)^{-4} d x d t\right)^{3 / 5} \\
& \quad \cdot\left(\int_{b-2^{-2 m}}^{b} \int_{R^{3}}\left(|x-a|+2^{-m}\right)^{-4} d x d t\right)^{2 / 5} \\
& \leqq C_{9}\left(\int_{b-2^{-2 m}}^{b} \int_{R^{3}}|u(x, t)|^{10 / 3}\left(|x-a|+2^{-m}\right)^{-4} d x d t\right)^{3 / 5} 2^{-2 m / 5} .
\end{aligned}
$$

Definition 5.18. If $f$ is a function defined on $R^{3} \times R$ and $g$ is a function on $R^{3}$ then we set

$$
(f * g)(x, t)=\int_{R^{3}} f(y, t) g(x-y) d y
$$

whenever the integral makes sense.

Lemma 5.19. If $f$ is a $C^{\infty}$ function with compact support from $R^{3} \times R$ into $R^{3}$ such that $\operatorname{div}(f)=0$ and the distance between the support of $f$ and the complement of $U \times R$ exceeds $2 \varepsilon$ then there exist real numbers $a<b$ and $a C^{\infty}$ function $g: R^{3} \times R \rightarrow R^{3}$ such that $\operatorname{curl}(g)=f, g(x, s)=0$ if $s \notin[a, b]$, and

$$
\begin{aligned}
- & \int_{R^{3}}\left[w_{i}^{0}(x)\right]\left[\left(f_{i} * \Psi\right)(x, 0)\right] d x \\
= & \int_{0}^{\infty} \int_{R^{3}}\left[u_{i}(x, s)\right]\left[D_{t} f_{i}(x, s)+\Delta\left(f_{i} * \Omega * \Omega\right)(x, s)\right] d x d s \\
& \quad+\int_{0}^{\infty} \int_{R^{3}}\left[u_{j}(x, s) z_{i}(x, s)-z_{j}(x, s) u_{i}(x, s)\right]\left[D_{j}\left(g_{i} * \Psi * \Psi\right)(x, s)\right] d x d s .
\end{aligned}
$$

Proof. We can find $a<b$ such that $f(x, s)=0$ if $s \notin[a, b]$. Recalling Definition 5.8 we set $g=-\operatorname{curl}(f * J)$ and obtain

$$
\begin{aligned}
\operatorname{curl}(g) & =-\operatorname{curl}(\operatorname{curl}(f * J))=\Delta(f * J)-\operatorname{grad}(\operatorname{div}(f * J)) \\
& =f-\operatorname{grad}((\operatorname{div}(f)) * J)=f .
\end{aligned}
$$

If $s>0$ then Definition 5.10, Definition 5.14, the fact that the function $h(x)$ $=(f * \Psi)(x, s)$ is an element of $W$, and the argument in the proof of Lemma 5.13 
yield

$$
\begin{aligned}
\int\left[\left(D_{t} w_{i}^{\prime}(s)\right)(x)\right]\left[f_{i}(x, s)\right] d x \\
=\int\left[\left(D_{t} w_{i}(s)\right)(x)\right]\left[\left(f_{i} * \Psi\right)(x, s)\right] d x \\
=-\int\left[\left(\left(w_{j}^{\prime}(s) D_{j}\left(w_{i}^{\prime}(s)\right)\right) * \Psi\right)(x)\right]\left[\left(f_{i} * \Psi\right)(x, s)\right] d x \\
\quad+\int\left[\Delta\left(w_{i}(s) * \Omega * \Omega\right)(x)\right]\left[\left(f_{i} * \Psi\right)(x, s)\right] d x \\
=-\int\left[u_{j}(x, s) D_{j} z_{i}(x, s)-z_{j}(x, s) D_{j} u_{i}(x, s)\right]\left[\left(g_{i} * \Psi * \Psi\right)(x, s)\right] d x \\
\quad+\int\left[\Delta u_{i}(x, s)\right]\left[\left(f_{i} * \Omega * \Omega\right)(x, s)\right] d x \\
=\int\left[u_{j}(x, s) z_{i}(x, s)-z_{j}(x, s) u_{i}(x, s)\right]\left[D_{j}\left(g_{i} * \Psi * \Psi\right)(x, s)\right] d x \\
\quad+\int\left[u_{i}(x, s)\right]\left[\Delta\left(f_{i} * \Omega * \Omega\right)(x, s)\right] d x .
\end{aligned}
$$

The conclusion follows by integrating over $s$ and using Lemma 5.6.

6.

Let $\varepsilon_{1}, \varepsilon_{2}, \varepsilon_{3}, \ldots$ be an infinite sequence of positive numbers with limit zero. We can find an infinite sequence $\alpha_{1}, \alpha_{2}, \alpha_{3}, \ldots$ of positive numbers such that $\alpha_{n}<\varepsilon_{n}$ and (5.1) is satisfied whenever $(\alpha, \varepsilon)=\left(\alpha_{n}, \varepsilon_{n}\right)$. For each $n$ we can set $\alpha=\alpha_{n}$ and $\varepsilon=\varepsilon_{n}$ and use all of the definitions and results of Sect. 5. The corresponding functions $u$ and $z$ introduced in Definition 5.14 will be denoted by $u^{n}$ and $z^{n}$ [so that $z^{n}=\operatorname{curl}\left(u^{n}\right)$ ]. From (5.4), Young's inequality $\|w(s) * \Psi\|_{2} \leqq\|w(s)\|_{2}\|\Psi\|_{1}$, Lemma 5.17, and (5.5) we obtain

$$
\begin{gathered}
\int_{R^{3}}\left|u^{n}(x, t)\right|^{2} d x \leqq\left\|w^{0}\right\|_{2}^{2} \text { if } t \geqq 0, \\
\int_{0}^{\infty} \int_{R^{3}}\left|u^{n}(x, t)\right|^{10 / 3} d x d t \leqq C_{8}\left\|w^{0}\right\|_{2}^{10 / 3}, \\
\int_{0}^{\infty} \int_{R^{3}}\left|D u^{n}(x, t)\right|^{2} d x d t \leqq(1 / 2)\left\|w^{0}\right\|_{2}^{2} .
\end{gathered}
$$

By passing to a subsequence, we may assume that $u^{n}$ converges weakly in $L^{10 / 3}$ to a function $u$ and that $D u^{n}$ converges weakly in $L^{2}$ to $D u$. Hence curl $\left(u^{n}\right)$ converges weakly in $L^{2}$ to $\operatorname{curl}(u)$.

Definition 6.1. For every integer $m$ we fix a countable set $A(m) \subset R^{3}$ with the following properties : (a) Every $x \in R^{3}$ is contained in the interior of $B\left(a, 2^{-m-3}\right)$ for some $a \in A(m)$; (b) $\left\{B\left(a, 2^{-m-4}\right): a \in A(m)\right\}$ is a collection of disjointed sets. We also set $B(m)=\left\{2^{-2 m}+2^{-2 m-6} i: i\right.$ is a positive integer $\}$. Recalling Theorems 4.2 and 5.12 , we define $D(m)=\{(a, b) \in A(m) \times B(m)$ : there exists an integer $N$ such that (6.4) is false for all $n \geqq N\}$.

$$
\begin{aligned}
& 2^{m} I\left(\left|D u^{n}\right|^{2}, K\left(a, b, 2^{-m+2}, 2^{-2 m}\right)\right) \\
& +2^{-m}\left(\int_{b-2^{-2 m}}^{b} \int_{R^{3}}\left|u^{n}(x, t)\right|^{2}\left(|x-a|+2^{-m}\right)^{-4} d x d t\right) \leqq C_{5}\left(C_{7}\right) .
\end{aligned}
$$

The proof of the next lemma is left to the reader. 
Lemma 6.2. There exists an absolute constant $C_{10}$ with the following properties:

$$
\begin{aligned}
& \sum_{a \in A(m)}\left(|x-a|+2^{-m}\right)^{-4} \leqq C_{10} 2^{4 m} \text { for all } x \in R^{3}, \\
& \sum_{(a, b) \in A(m) \times B(m)}\left(\int_{b-2^{-2 m}}^{b} \int_{R^{3}} f(x, t)\left(|x-a|+2^{-m}\right)^{-4} d x d t\right) \\
& \leqq C_{10} 2^{4 m} I\left(f, R^{3} \times R^{+}\right), \\
& \sum_{(a, b) \in A(m) \times B(m)} I\left(f, K\left(a, b, 2^{-m+2}, 2^{-2 m}\right)\right) \leqq C_{10} I\left(f, R^{3} \times R^{+}\right)
\end{aligned}
$$

for any integrable function $f \geqq 0$.

Lemma 6.3. If $m \geqq 0$ then the number of elements in the set $D(m)$ is less than

$$
M=C_{11}^{-1} 2^{5 m / 3} C_{10}\left((1 / 2)\left\|w^{0}\right\|_{2}^{2}+C_{9}^{5 / 3} C_{8}\left\|w^{0}\right\|_{2}^{10 / 3}\right),
$$

where $C_{11}$ is the minimum of $(1 / 2) C_{5}\left(C_{7}\right)$ and $\left((1 / 2) C_{5}\left(C_{7}\right)\right)^{5 / 3}$.

Proof. If this is false then we can find $k$ distinct elements in $D(m)$, where $k$ is the smallest integer greater than or equal to $M$. We denote these elements by $\left(a_{i}, b_{i}\right)$, $i \in\{1,2, \ldots, k\}$. There exists an integer $N$ such that (6.4) is false whenever $n \geqq N$ and $(a, b)$ is one of the $\left(a_{i}, b_{i}\right)$. This implies that we have either

$$
2^{m} I\left(\left|D u^{n}\right|^{2}, K\left(a_{i}, b_{i}, 2^{-m+2}, 2^{-2 m}\right)\right)>(1 / 2) C_{5}\left(C_{7}\right)
$$

or

$$
2^{-m}\left(\int_{b_{i}-2^{-2 m}}^{b_{i}} \int_{R^{3}}\left|u^{n}(x, t)\right|^{2}\left(\left|x-a_{i}\right|+2^{-m}\right)^{-4} d x d t\right)>(1 / 2) C_{5}\left(C_{7}\right)
$$

if $n \geqq N$ and $1 \leqq i \leqq k$. Since (6.6) is equivalent to

$$
\begin{aligned}
& 2^{-5 m / 3}\left(\int_{b_{i}-2^{-2 m}}^{b_{i}} \int_{R^{3}}\left|u^{n}(x, t)\right|^{2}\left(\left|x-a_{i}\right|+2^{-m}\right)^{-4} d x d t\right)^{5 / 3} \\
& >\left((1 / 2) C_{5}\left(C_{7}\right)\right)^{5 / 3}
\end{aligned}
$$

the sum of the left hand sides of (6.5) and (6.7) must exceed $C_{11}$ for every $n \geqq N$ and $1 \leqq i \leqq k$. Now Lemma 6.2, Lemma 5.17, (6.3), Lemma 6.2 again, $m \geqq 0$, and (6.2) yield

$$
\begin{aligned}
C_{11} k< & \sum_{i=1}^{k} 2^{m} I\left(\left|D u^{N}\right|^{2}, K\left(a_{i}, b_{i}, 2^{-m+2}, 2^{-2 m}\right)\right) \\
& +\sum_{i=1}^{k} 2^{-5 m / 3}\left(\int_{b_{i}-2-2 m}^{b_{i}} \int_{R^{3}}\left|u^{N}(x, t)\right|^{2}\left(\left|x-a_{i}\right|+2^{-m}\right)^{-4} d x d t\right)^{5 / 3} \\
\leqq & 2^{m} C_{10} I\left(\left|D u^{N}\right|^{2}, R^{3} \times R^{+}\right) \\
& +\sum_{i=1}^{k} 2^{-7 m / 3} C_{9}^{5 / 3}\left(\int_{b_{2}-2^{-2 m}}^{b_{i}} \int_{R^{3}}\left|u^{N}(x, t)\right|^{10 / 3}\left(\left|x-a_{i}\right|+2^{-m}\right)^{-4} d x d t\right) \\
\leqq & 2^{m} C_{10}(1 / 2)\left\|w^{0}\right\|_{2}^{2}+2^{-7 m / 3} C_{9}^{5 / 3} C_{10} 2^{4 m}\left(\int_{0}^{\infty} \int_{R^{3}}\left|u^{N}(x, t)\right|^{10 / 3} d x d t\right) \\
\leqq & 2^{5 m / 3} C_{10}(1 / 2)\left\|w^{0}\right\|_{2}^{2}+2^{5 m / 3} C_{9}^{5 / 3} C_{10} C_{8}\left\|w^{0}\right\|_{2}^{10 / 3} .
\end{aligned}
$$

This contradicts the definition of $k$. 
Lemma 6.4. If $b \in B(m)$ then the number of elements in the set

$$
A=\{a \in A(m):(a, b) \in D(m)\}
$$

is less than

$$
M^{\prime}=\left(C_{5}\left(C_{7}\right)\right)^{-1} 2^{m} C_{10}\left\|w^{0}\right\|_{2}^{2}(3 / 2) .
$$

Proof. If this is false then we can find $k$ distinct elements of $A$, where $k$ is the smallest integer greater than or equal to $M^{\prime}$. We denote these elements by $a_{i}$, $i \in\{1,2, \ldots, k\}$. There exists an integer $N$ such that (6.4) is false whenever $n \geqq N, a$ is one of the $a_{i}$, and $b$ in the hypothesis. Hence the first and third inequalities in Lemma 6.2, (6.3), and (6.1) yield

$$
\begin{aligned}
C_{5}\left(C_{7}\right) k< & \sum_{i=1}^{k} 2^{m} I\left(\left|D u^{N}\right|^{2}, K\left(a_{i}, b, 2^{-m+2}, 2^{-2 m}\right)\right) \\
& +\sum_{i=1}^{k} 2^{-m}\left(\int_{b-2^{-2 m}}^{b} \int_{R^{3}}\left|u^{N}(x, t)\right|^{2}\left(\left|x-a_{i}\right|+2^{-m}\right)^{-4} d x d t\right) \\
\leqq & 2^{m} C_{10} I\left(\left|D u^{N}\right|^{2}, R^{3} \times R^{+}\right)+2^{-m} C_{10} 2^{4 m}\left(\int_{b-2^{-2 m}}^{b} \int_{R^{3}}\left|u^{N}(x, t)\right|^{2} d x d t\right) \\
\leqq & 2^{m} C_{10}(1 / 2)\left\|w^{0}\right\|_{2}^{2}+2^{-m} C_{10} 2^{4 m} 2^{-2 m}\left\|w^{0}\right\|_{2}^{2}=2^{m} C_{10}\left\|w^{0}\right\|_{2}^{2}(3 / 2) .
\end{aligned}
$$

As before, this contradicts the definition of $k$.

Definition 6.5. For any nonempty subset $B$ of $R^{3} \times R$ we define

$$
\operatorname{diam}(B)=\sup \left\{\left(|a-c|^{2}+|b-d|^{2}\right)^{1 / 2}:(a, b) \in B \text { and }(c, d) \in B\right\}
$$

and we set $\operatorname{diam}(\phi)=0$. Suppose $0<d \leqq 4$ and $A$ is a subset of $R^{3} \times R$. Then for every $\delta>0$ we define $\phi_{\delta}^{d}(\mathrm{~A})$ to be the infimum of all numbers of the form

$$
\sum_{i=1}^{\infty}\left(\Gamma(1 / 2)^{d} / \Gamma((d / 2)+1)\right) 2^{-d}\left(\operatorname{diam}\left(A_{i}\right)\right)^{d}
$$

where $A_{i}$ is a subset of $R^{3} \times R, A \subset \bigcup_{i=1}^{\infty} A_{i}$, and $\operatorname{diam}\left(A_{i}\right) \leqq \delta$. Observe that $\phi_{\delta}^{d}(A)$ $\geqq \phi_{\eta}^{d}(A)$ if $\delta \leqq \eta$. This allows us to define $H^{d}(A)=\lim _{\delta \rightarrow 0} \phi_{\delta}^{d}(\mathrm{~A})$. $\mathrm{H}^{d}(\mathrm{~A})$ is called the $d$ dimensional Hausdorff measure of $A$. For additional details, see [2].

Lemma 6.6. There exist absolute constants $C_{12}, C_{13}$, and $C_{14}$ with the following property: For every integer $k \geqq 0$ there exists a compact set $S(k) \subset R^{3} \times R^{+}$such that $S(k) \subset S(k+1)$

(a) $H^{5 / 3}(S(k)) \leqq C_{12}\left\|w^{0}\right\|_{2}^{2}+C_{13}\left\|w^{0}\right\|_{2}^{10 / 3}$,

(b) $H^{1}\left(S(k) \cap\left(R^{3} \times\{t\}\right)\right) \leqq C_{14}\left\|w^{0}\right\|_{2}^{2}$ if $t>0$,

(c) if $(c, d) \in\left(R^{3} \times\left[2^{-2 k}, \infty\right)\right) \sim S(k)$ then there exist an integer $m \geqq k$ and $(a, b) \in A(m) \times B(m)$ such that $(c, d)$ is in the interior of $K\left(a, b, 2^{-m-3}, 2^{-2 m-5}\right)$ and (6.4) is true for infinitely many $n$.

Proof. For every integer $m \geqq 0$ we let $T(m) \subset R^{3} \times R^{+}$be the union of all the sets $K\left(a, b, 2^{-m-3}, 2^{-2 m-5}\right)$ such that $(a, b) \in D(m)$. Then we let $S(k)$ be the intersection of all $T(m)$ such that $m \geqq k$. Lemma 6.3 implies that $D(m)$ is finite. Hence every $T(m)$ is compact, and this implies that $S(k)$ is compact. If $(c, d) \notin S(k)$ then $(c, d) \notin T(m)$ for some $m \geqq k$. If, in addition, $(c, d) \in R^{3} \times\left[2^{-2 k}, \infty\right)$, then $d \geqq 2^{-2 k} \geqq 2^{-2 m}$ and hence there exists $(a, b) \in A(m) \times B(m)$ such that $(c, d)$ is in the interior of 
$K\left(a, b, 2^{-m-3}, 2^{-2 m-5}\right)$. Since $(c, d) \notin T(m)$, we must have $(a, b) \notin D(m)$. This proves (c). We have $\operatorname{diam}\left(K\left(a, b, 2^{-m-3}, 2^{-2 m-5}\right)\right)<2^{-m}$ when $m \geqq 0$. If $k$ is given then, for every $m \geqq k, S(k)$ is covered by the sets $K\left(a, b, 2^{-m-3}, 2^{-2 m-5}\right)$ where $(a, b) \in D(m)$. Hence Lemma 6.3 yields

$$
\begin{aligned}
\phi_{\delta}^{5 / 3}(S(k)) & \leqq \sum_{(a, b) \in D(m)} C\left(\operatorname{diam}\left(K\left(a, b, 2^{-m-3}, 2^{-2 m-5}\right)\right)\right)^{5 / 3} \\
& \leqq C_{12}\left\|w^{0}\right\|_{2}^{2}+C_{13}\left\|w^{0}\right\|_{2}^{10 / 3}
\end{aligned}
$$

whenever $\delta \geqq 2^{-m}$. Taking the limit as $m \rightarrow \infty$, we obtain (a). Now suppose that $k \geqq 0$ is an integer and $t>0$. For every $m \geqq k, T(m) \cap\left(R^{3} \times\{t\}\right)$ is covered by a collection of sets $K\left(a, b, 2^{-m-3}, 2^{-2 m-5}\right)$ such that $(a, b) \in D(m)$ and $b$ takes at most three distinct values [since we can discard those sets $K\left(a, b, 2^{-m-3}, 2^{-2 m-5}\right)$ which do not intersect $\left.R^{3} \times\{t\}\right]$. Hence we can use the argument of (6.8) and Lemma 6.4 to conclude

$$
\phi_{\delta}^{1}\left(S(k) \cap\left(R^{3} \times\{t\}\right)\right) \leqq \phi_{\delta}^{1}\left(T(m) \cap\left(R^{3} \times\{t\}\right)\right) \leqq C_{14}\left\|w^{0}\right\|_{2}^{2}
$$

when $\delta \geqq 2^{-m}$. We obtain (b) by taking the limit as $m \rightarrow \infty$.

Lemma 6.7. Suppose $\beta>0$ and $V$ is an open subset of $R^{3}$ such that the closure of $V$ is compact and the closure of $V$ is contained in $U$. Then there exists an integer $k \geqq 0$ and a function $z:\left(V \times\left[2^{-2 k}, \infty\right)\right) \sim S(k) \rightarrow R^{3}$ such that

$$
2^{-2 k} \leqq \beta, \quad z(x, t)=(\operatorname{curl}(u))(x, t)
$$

for almost every $(\dot{x}, t)$ in the domain of $z$, and $z$ is a continuous function.

Proof. We let $\delta$ be the distance between the closure of $V$ and the complement of $U$. The number $\delta$ is positive because the closure of $V$ is compact. There exists $R>0$ such that $4 R<\delta$. Now we can find an integer $k$ large enough so that $k \geqq 0,2^{-2 k} \leqq \beta$, $2^{-k}<R / 2,4 R+2^{-k+1}<\delta$, and

$$
2^{-2 k}\left\|w^{0}\right\|_{2}+2^{-2 k}\left\|w^{0}\right\|_{2} R^{-7 / 2}+\left\|w^{0}\right\|_{2} R^{-3 / 2} \leqq C_{5}\left(C_{7}\right) 2^{k}
$$

Suppose $(x, t) \in\left(V \times\left[2^{-2 k}, \infty\right)\right) \sim S(k)$. Lemma 6.6 yields an integer $m \geqq k$ and $(a, b) \in A(m) \times B(m)$ such that $(x, t)$ is in the interior of $K\left(a, b, 2^{-m-3}, 2^{-2 m-5}\right)$ and (6.4) is true for infinitely many $n$. We can find an infinite sequence $n_{1}<n_{2}<n_{3}<\ldots$ such that (6.4) is true for every $n=n_{i}$ and, in addition, $4 R+2^{-k+1}+4 \varepsilon_{n}<\delta$ for every $n=n_{i}$. We now establish the following claim: If $n$ is one of the $n_{i}$, $(c, d) \in K\left(a, b, 2^{-m}, 2^{-2 m}\right), 0<h \leqq 2^{-m}$, and $d>h^{2}$ then

$$
\begin{aligned}
& C_{7}^{-1}\left|u^{n}(c, d)\right| \\
& \leqq \\
& \quad \int_{d-h^{2}}^{d} \int_{R^{3}}\left|u^{n}(y, s)\right|^{2}\left(|y-c|+(d-s)^{1 / 2}\right)^{-4} d y d s \\
& \quad+\int_{d-h^{2}}^{d} \int_{R^{3}}\left|u^{n}(y, s)\right|(|y-c|+h)^{-4} h^{-1} d y d s+C_{5}\left(C_{7}\right) 2^{m} .
\end{aligned}
$$


If $|y-c| \leqq 4 R+4 \varepsilon_{n_{1}}$ then

$$
\begin{aligned}
|y-x| & \leqq|y-c|+|c-a|+|a-x| \leqq 4 R+4 \varepsilon_{n_{i}}+2^{-m}+2^{-m-3} \\
& <4 R+4 \varepsilon_{n_{\imath}}+2^{-k+1}<\delta
\end{aligned}
$$

Since $x \in V$, we conclude $y \in U$. In particular, we have $c \in U$. In addition, we have $0<h \leqq 2^{-m} \leqq 2^{-k}<R / 2$. Now we can use $k \leqq m$ and Theorem 5.12 to conclude (6.10). We use (6.1), (6.3), and Theorem 4.2 with $H=C_{7}$ and $\Gamma=C_{5}\left(C_{7}\right) 2^{m}$ to conclude

$$
\left|u^{n}(c, d)\right| \leqq C_{6}\left(C_{7}\right) 2^{m} \text { if }(c, d) \in K\left(a, b, 2^{-m-2}, 2^{-2 m-4}\right) \text { and } n=n_{i} \text { for some } i .
$$

Since (6.4) is true for all $n=n_{i}$, the collection of numbers

$$
\left\{I\left(\left|D u^{n}\right|^{2}, K\left(a, b, 2^{-m-2}, 2^{-2 m-4}\right)\right): n=n_{i} \text { for some } i\right\}
$$

is bounded. Combining this with (6.11) and Theorem 5.16 we conclude that the collection of functions $\left\{\operatorname{curl}\left(u^{n}\right): n=n_{i}\right.$ for some $i$ and $\left.\varepsilon_{n}<\left(2^{-m-2}\right) / 64\right\}$ is uniformly bounded and equicontinuous on $K\left(a, b, 2^{-m-3}, 2^{-2 m-5}\right)$. By Ascoli's theorem, a subsequence converges uniformly to a continuous function. This limit function must coincide almost everywhere with the weak limit $\operatorname{curl}(u)$ of the original sequence $\operatorname{curl}\left(u^{n}\right)$. This means that we can make curl $(u)$ continuous on the interior of $K\left(a, b, 2^{-m-3}, 2^{-2 m-5}\right)$ by redefining it on a set of Lebesgue measure zero. The conclusion of the lemma follows easily.

Theorem 6.8. There exists a set $S \subset U \times R^{+}$such that

(a) if $K$ is a compact subset of $U \times R^{+}$then $K \cap S$ is compact,

(b) the function curl $(u)$ can be modified on a set of Lebesgue measure zero so that it becomes continuous on $\left(U \times R^{+}\right) \sim S$,

(c) $H^{5 / 3}(S) \leqq C_{12}\left\|w^{0}\right\|_{2}^{2}+C_{13}\left\|w^{0}\right\|_{2}^{10 / 3}$

(d) $H^{1}\left(S \cap\left(R^{3} \times\{t\}\right)\right) \leqq C_{14}\left\|w^{0}\right\|_{2}^{2}$ if $t>0$.

Proof. We construct an infinite sequence $V_{1}, V_{2}, V_{3}, \ldots$ of open subsets of $U$ such that closure $\left(V_{n}\right) \subset V_{n+1}$, closure $\left(V_{n}\right)$ is compact, and the union of the $V_{n}$ is equal to $U$. We will use the abbreviation $2^{-2 k}=b(k)$. Using Lemma 6.7 we obtain an increasing sequence $k_{1}<k_{2}<k_{3}<\ldots$ of nonnegative integers such that the restriction of $\operatorname{curl}(u)$ to $\left(V_{n} \times\left[b\left(k_{n}\right), \infty\right)\right) \sim S\left(k_{n}\right)$ is equal almost everywhere to a continuous function. We define

$$
S=S\left(k_{1}\right) \cup\left(\bigcup_{n=1}^{\infty}\left(S\left(k_{n+1}\right) \sim\left(V_{n} \times\left(b\left(k_{n}\right), \infty\right)\right)\right)\right) .
$$

If $K$ is a compact subset of $U \times R^{+}$then there exists an integer $N$ such that $K \subset V_{n} \times\left(b\left(k_{n}\right), \infty\right)$ for all $n>N$. Hence

$$
S \cap K=\left(S\left(k_{1}\right) \cap K\right) \cup\left(\bigcup_{n=1}^{N}\left(\left(S\left(k_{n+1}\right) \sim\left(V_{n} \times\left(b\left(k_{n}\right), \infty\right)\right)\right) \cap K\right)\right)
$$


which is a union of finitely many compact sets. This proves (a). Now suppose $(a, b) \in\left(U \times R^{+}\right) \sim S$. We have two possibilities: (1) $(a, b) \in V_{1} \times\left(b\left(k_{1}\right), \infty\right)$; (2) there exists $n$ such that $(a, b) \in V_{n+1} \times\left(b\left(k_{n+1}\right), \infty\right)$ but $(a, b) \notin V_{n} \times\left(b\left(k_{n}\right), \infty\right)$. If (1) holds then $(a, b) \in\left(V_{1} \times\left(b\left(k_{1}\right), \infty\right)\right) \sim S\left(k_{1}\right)$. If (2) holds then $(a, b) \in\left(V_{n+1} \times\left(b\left(k_{n+1}\right), \infty\right)\right)$ $\sim S\left(k_{n+1}\right)$ because $(a, b) \notin S$ implies $(a, b) \notin S\left(k_{n+1}\right) \sim\left(V_{n} \times\left(b\left(k_{n}\right), \infty\right)\right)$, and combining this with (2) yields $(a, b) \notin S\left(k_{n+1}\right)$. In either case, $(a, b)$ is contained in an open set on which curl $(u)$ coincides almost everywhere with a continuous function. This proves (b). Since Hausdorff measure is a Borel measure and $S(k) \subset S(k+1)$, we obtain (c) and (d) from Lemma 6.6 and the following:

$$
\begin{aligned}
H^{5 / 3}(S) & \leqq H^{5 / 3}\left(\bigcup_{n=1}^{\infty} S\left(k_{n}\right)\right)=\lim _{n \rightarrow \infty} H^{5 / 3}\left(S\left(k_{n}\right)\right) \\
& \leqq C_{12}\left\|w^{0}\right\|_{2}^{2}+C_{13}\left\|w^{0}\right\|_{2}^{10 / 3}, \\
H^{1}\left(S \cap\left(R^{3} \times\{t\}\right)\right) & \leqq H^{1}\left(\left(\bigcup_{n=1}^{\infty} S\left(k_{n}\right)\right) \cap\left(R^{3} \times\{t\}\right)\right) \\
& =\lim _{n \rightarrow \infty} H^{1}\left(S\left(k_{n}\right) \cap\left(R^{3} \times\{t\}\right)\right) \leqq C_{14}\left\|w^{0}\right\|_{2}^{2} \text { if } t>0 .
\end{aligned}
$$

Definition 6.9. For every integer $m$ and every positive integer $n$ we set $E(m, n)$ $=\{b \in B(m):(6.4)$ is false for some $a \in A(m)\}$.

Lemma 6.10. The number of elements in the set $E(m, n)$ is less than the number $M$ described in Lemma 6.3.

Proof. If this is false then we can find $k$ distinct elements in $E(m, n)$, where $k$ is the smallest integer greater than or equal to $M$. We denote these elements by $b_{i}$, $i \in\{1,2, \ldots, k\}$. For each $i$, there exists $a_{i} \in A(m)$ such that $(6.4)$ is false when $(a, b)$ is replaced by $\left(a_{i}, b_{i}\right)$. Carrying out the argument in the proof of Lemma 6.3 (the only difference being that we are now dealing with a single $n$, which only simplifies things), we obtain a contradiction.

Lemma 6.11. If $V$ is an open subset of $R^{3}$ such that the closure of $V$ is compact and the closure of $V$ is contained in $U, \eta>0$, and $0<\beta<T<\infty$ then there exists a closed set $F \subset R^{+}$such that the Lebesgue measure of $F$ is at most $\eta$ and a subsequence of the sequence curl $\left(u^{n}\right)$ converges uniformly on $V \times((\beta, T) \sim F)$.

Proof. We let $\delta>0$ be the distance between the closure of $V$ and the complement of $U$. We find $R>0$ such that $4 R<\delta$ and we find an integer $m$ large enough so that $m \geqq 0,2^{-2 m} \leqq \beta, 2^{-m}<R / 2,4 R+2^{-m+1}<\delta$,

$$
2^{-2 m}\left\|w^{0}\right\|_{2}+2^{-2 m}\left\|w^{0}\right\|_{2} R^{-7 / 2}+\left\|w^{0}\right\|_{2} R^{-3 / 2} \leqq C_{5}\left(C_{7}\right) 2^{m},
$$

and (see Lemma 6.3)

$$
2^{-2 m-5} C_{11}^{-1} 2^{5 m / 3} C_{10}\left((1 / 2)\left\|w^{0}\right\|_{2}^{2}+C_{9}^{5 / 3} C_{8}\left\|w^{0}\right\|_{2}^{10 / 3}\right) \leqq \eta .
$$

We let $E^{\prime}(m, n)=\left\{b \in E(m, n): b \leqq T+2^{-2 m}\right\}$. Since $\left\{b \in B(m): b \leqq T+2^{-2 m}\right\}$ is a finite set which contains $E^{\prime}(m, n)$ for every $n$, we conclude that, as $n$ varies, $E^{\prime}(m, n)$ can only be one of a finite number of different sets. Hence there exists an infinite 
sequence $n_{1}<n_{2}<n_{3}<\ldots$ of positive integers such that

$$
E^{\prime}\left(m, n_{1}\right)=E^{\prime}\left(m, n_{2}\right)=E^{\prime}\left(m, n_{3}\right)=\ldots
$$

Setting $E^{\prime}=E^{\prime}\left(m, n_{i}\right)$, we define $F$ to be the union of the intervals $\left[b-2^{-2 m-5}, b\right]$ for $b \in E^{\prime}$. From Lemma 6.10 and (6.12) we conclude that the Lebesgue measure of $F$ is at most $\eta$. If $(x, t) \in V \times((\beta, T) \sim F)$ then $(x, t)$ is contained in the interior of $K\left(a, b, 2^{-m-3}, 2^{-2 m-5}\right)$ for some $(a, b) \in A(m) \times B(m)$. If $b \in E^{\prime}$ then $t \in\left[b-2^{-2 m-5}, b\right] \subset F$, which contradicts the choice of $(x, t)$. Hence we conclude $b \notin E^{\prime}$. From $b-2^{-2 m-5}<t<T$ we obtain $b<T+2^{-2 m}$. This implies that $b \notin E\left(m, n_{i}\right)$ for all $i$ and, in particular, that (6.4) is true for every $n=n_{i}$. Since $V \times((\beta, T) \sim F)$ is bounded, we obtain that $V \times((\beta, T) \sim F)$ is covered by the interiors of a finite collection of sets of the form $K\left(a, b, 2^{-m-3}, 2^{-2 m-5}\right)$ such that $(a, b) \in A(m) \times B(m)$ and (6.4) is true for every $n=n_{i}$. The rest follows from the argument in the proof of Lemma 6.7.

Lemma 6.12. If $f$ is a $C^{\infty}$ function with compact support from $R^{3} \times R$ into $R^{3}$ such that $\operatorname{div}(f)=0$ and the support of $f$ is contained in $U \times R$ then there exist real numbers $a<b$ and $a C^{\infty}$ function $g: R^{3} \times R \rightarrow R^{3}$ such that $\operatorname{curl}(g)=f, g(x, s)=0$ if $s \notin[a, b]$, and

$$
\begin{aligned}
& -\int_{R^{3}} w_{i}^{0}(x) f_{i}(x, 0) d x \\
& =\int_{0}^{\infty} \int_{R^{3}}\left[u_{i}(x, s)\right]\left[D_{t} f_{i}(x, s)+\Delta f_{i}(x, s)\right] d x d s \\
& \quad+\int_{0}^{\infty} \int_{R^{3}}\left[u_{j}(x, s)\right]\left[(\operatorname{curl}(u))_{i}(x, s)\right]\left[D_{j} g_{i}(x, s)\right] d x d s \\
& \quad+\int_{0}^{\infty} \int_{R^{3}}-\left[(\operatorname{curl}(u))_{j}(x, s)\right]\left[u_{i}(x, s)\right]\left[D_{j} g_{i}(x, s)\right] d x d s .
\end{aligned}
$$

Proof. The $a, b, g$ found in the proof of Lemma 5.19 depend only on $f$. Therefore we can use Lemma 5.19, Definition 5.1, and Definition 5.2 to find real numbers $a<b$ and a $C^{\infty}$ function $g: R^{3} \times R \rightarrow R^{3}$ such that $\operatorname{curl}(g)=f, g(x, s)=0$ if $s \notin[a, b]$, and

$$
\begin{aligned}
-\int_{R^{3}} & {\left[w_{i}^{0}(x)\right]\left[\left(f_{i} * \theta_{\varepsilon_{n}}^{\prime} * \theta_{\alpha_{n}}^{\prime}\right)(x, 0)\right] d x } \\
& =\int_{0}^{\infty} \int_{R^{3}}\left[u_{i}^{n}(x, s)\right]\left[D_{t} f_{i}(x, s)+\Delta\left(f_{i} * \theta_{\alpha_{n}}^{\prime} * \theta_{\alpha_{n}}^{\prime}\right)(x, s)\right] d x d s \\
& +\int_{0}^{\infty} \int_{R^{3}}\left[u_{j}^{n}(x, s) z_{i}^{n}(x, s)\right]\left[D_{j}\left(g_{i} * \theta_{\varepsilon_{n}}^{\prime} * \theta_{\alpha_{n}}^{\prime} * \theta_{\varepsilon_{n}}^{\prime} * \theta_{\alpha_{n}}^{\prime}\right)(x, s)\right] d x d s \\
& +\int_{0}^{\infty} \int_{R^{3}}-\left[z_{j}^{n}(x, s) u_{i}^{n}(x, s)\right]\left[D_{j}\left(g_{i} * \theta_{\varepsilon_{n}}^{\prime} * \theta_{\alpha_{n}}^{\prime} * \theta_{\varepsilon_{n}}^{\prime} * \theta_{\alpha_{n}}^{\prime}\right)(x, s)\right] d x d s
\end{aligned}
$$

is satisfied for sufficiently large $n$. Since $f$ is $C^{\infty}$ with compact support and $u^{n}$ converges to $u$ weakly in $L^{10 / 3}$, the first two integrals in (6.14) converge to the first 
two integrals in (6.13) as $n \rightarrow \infty$. To complete the proof we have to show that for every $\varepsilon>0$ and every positive integer $N$ there exists an integer $n \geqq N$ such that the sum of the last two integrals of (6.14) is within $\varepsilon$ of the sum of the last two integrals of (6.13). Suppose $\varepsilon$ and $N$ are given. We set $\Phi_{n}=\theta_{\varepsilon_{n}}^{\prime} * \theta_{\alpha_{n}}^{\prime} * \theta_{\varepsilon_{n}}^{\prime} * \theta_{\alpha_{n}}^{\prime}$ and use the boundedness of $U$ and the fact that $g(x, s)=0$ for $s \notin[a, b]$ to find a positive number $M$ such that $\left|D_{j}\left(g_{i} * \Phi_{n}\right)(x, s)\right| \leqq M$ and $\left|D_{j} g_{i}(x, s)\right| \leqq M$ if $x \in U$. We may as well assume that $b>0$ [otherwise the integrals in (6.13) are all zero]. Letting $m(U)$ be the Lebesgue measure of $U$, we find $\eta>0$ such that

$$
\text { (36) } M C_{8}^{3 / 10}\left\|w^{0}\right\|_{2}^{2}(\eta b+2 \eta(m(U)))^{1 / 5}(1 / 2)^{1 / 2}<\varepsilon / 4 .
$$

Since $U$ is bounded, we can find an open subset $V$ of $R^{3}$ such that the closure of $V$ is compact, the closure of $V$ is contained in $U$, and the Lebesgue measure of $U \sim V$ is at most $\eta$. Let $\beta$ be a positive number such that $\beta<\eta$ and $\beta<b$. Setting $T=b$, we can use Lemma 6.11 to find a closed set $F \subset R^{+}$such that the Lebesgue measure of $F$ is at most $\eta$ and there is an infinite sequence $n_{1}<n_{2}<n_{3}<\ldots$ of positive integers such that $N \leqq n_{1}$ and the subsequence

$$
\left(z^{n}=\operatorname{curl}\left(u^{n}\right): n=n_{1}, n_{2}, n_{3}, \ldots\right)
$$

converges uniformly on $V \times((\beta, T) \sim F)$. We set $E=V \times((\beta, T) \sim F)$ and let $h: R^{3} \times R^{+} \rightarrow R$ be the function defined by $h(x, s)=1$ if $(x, s) \in E$ and $h(x, s)=0$ otherwise. Setting $z=\operatorname{curl}(u)$, we conclude from the boundedness of $E$ that the subsequences

$$
\left(h(x, s) z_{i}^{n}(x, s) D_{j}\left(g_{i} * \Phi_{n}\right)(x, s): n=n_{1}, n_{2}, n_{3}, \ldots\right)
$$

and

$$
\left(h(x, s) z_{j}^{n}(x, s) D_{j}\left(g_{i} * \Phi_{n}\right)(x, s): n=n_{1}, n_{2}, n_{3}, \ldots\right)
$$

converge in $L^{10 / 7}$ norm to $h(x, s) z_{i}(x, s) D_{j} g_{i}(x, s)$ and $h(x, s) z_{j}(x, s) D_{j} g_{i}(x, s)$. Now the weak convergence in $L^{10 / 3}$ of $u^{n}$ to $u$ yields that a subsequence of

$$
\int_{E}\left[u_{j}^{n}(x, s) z_{i}^{n}(x, s)-z_{j}^{n}(x, s) u_{i}^{n}(x, s)\right]\left[D_{j}\left(g_{i} * \Phi_{n}\right)(x, s)\right] d x d s
$$

converges to

$$
\int_{E}\left[u_{j}(x, s) z_{i}(x, s)-z_{j}(x, s) u_{i}(x, s)\right]\left[D_{j} g_{i}(x, s)\right] d x d s .
$$

In particular, we can find arbitrarily large $n$ such that (6.16) and (6.17) differ by no more that $\varepsilon / 2$. The proof will be completed by setting $G=\left(R^{3} \times[0, T]\right) \sim E$ and showing that

$$
\begin{aligned}
& \left|\int_{G}\left[u_{j}^{n}(x, s) z_{i}^{n}(x, s)-z_{j}^{n}(x, s) u_{i}^{n}(x, s)\right]\left[D_{j}\left(g_{i} * \Phi_{n}\right)(x, s)\right] d x d s\right| \leqq \varepsilon / 4, \\
& \left|\int_{G}\left[u_{j}(x, s) z_{i}(x, s)-z_{j}(x, s) u_{i}(x, s)\right]\left[D_{j} g_{i}(x, s)\right] d x d s\right| \leqq \varepsilon / 4
\end{aligned}
$$


hold for sufficiently large $n$. Since $T=b$, the Lebesgue measure of $(U \times[0, T]) \sim E$ is at most the sum of the Lebesgue measure of $(U \sim V) \times[0, b]$ and the Lebesgue measure of $U \times([0, \beta] \cup F)$. Hence the Lebesgue measure of $(U \times[0, T]) \sim E$ is at most $\eta b+2 \eta(m(U))$. Since, by hypothesis, the boundary of $U$ has Lebesgue measure zero, we conclude that the Lebesgue measure of (closure $(U) \times[0, T]) \sim E$ is at most $\eta b+2 \eta(m(U))$. Let $K_{n}$ be the collection of all $x \in R^{3}$ such that the distance between $x$ and closure $(U)$ is at most $2 \varepsilon_{n}$, set $G_{n}=\left(K_{n} \times[0, T]\right) \sim E$, and let $a_{n}$ be the Lebesgue measure of $G_{n}$. The above and the boundedness of $U$ yield $\lim _{n \rightarrow \infty} a_{n} \leqq \eta b+2 \eta(m(U))$. Hence we can use (6.15) and find a positive integer $N^{\prime}$ such that

$$
\text { (36) } M C_{8}^{3 / 10}\left\|w^{0}\right\|_{2}^{2}\left(a_{n}\right)^{1 / 5}(1 / 2)^{1 / 2}<\varepsilon / 4 \quad \text { if } n \geqq N^{\prime} .
$$

Using Hölder's inequality, (6.2), and (6.3) we obtain

$$
\begin{aligned}
& \int_{G_{n}}\left|u_{j}^{n}(x, s) z_{i}^{n}(x, s)\right| d x d s \\
& \quad \leqq\left(\int_{G_{n}}\left|u_{j}^{n}(x, s)\right|^{2} d x d s\right)^{1 / 2}\left(\int_{G_{n}}\left|z_{i}^{n}(x, s)\right|^{2} d x d s\right)^{1 / 2} \\
& \leqq\left(\int_{G_{n}}\left|u_{j}^{n}(x, s)\right|^{10 / 3} d x d s\right)^{3 / 10}\left(a_{n}\right)^{1 / 5}(2)\left(\int_{G_{n}}\left|D u^{n}(x, s)\right|^{2} d x d s\right)^{1 / 2} \\
& \leqq C_{8}^{3 / 10}\left\|w^{0}\right\|_{2}\left(a_{n}\right)^{1 / 5}(2)(1 / 2)^{1 / 2}\left\|w^{0}\right\|_{2} .
\end{aligned}
$$

The same argument and the weak convergence of $u^{n}$ and $D u^{n}$ yield

$$
\int_{G_{n}}\left|u_{j}(x, s) z_{i}(x, s)\right| d x d s \leqq C_{8}^{3 / 10}\left\|w^{0}\right\|_{2}^{2}\left(a_{n}\right)^{1 / 5}(2)(1 / 2)^{1 / 2} .
$$

If $n$ is sufficiently large then (6.18) and (6.19) follow from the above, (6.20), and the fact that $u^{n}$ and $z^{n}$ are zero outside of $K_{n} \times R^{+}$. This completes the proof of the lemma.

Now we can tie these results together and obtain the conclusion of Theorem 1.2. The construction of $u$ yields that $u(x, t)=0$ for almost every $(x, t) \notin$ closure $(U) \times R^{+}$. Part (1) follows because we assume that the boundary of $U$ has Lebesgue measure zero. Part (2) also follows easily from the construction. Part (3) follows from Lemma 6.12 and integration by parts in the last two integrals of (6.13) [using the fact $\operatorname{div}(u)=0$ ]. The remainder follows from Theorem 6.8, (6.2), (6.3), and the definition of $u$.

\section{References}

1. Almgren, F.J., Jr.: Existence and regularity almost everywhere of solutions to elliptic variational problems with constraints. Memoirs of the American Mathematical Society 165. Providence, R.I.: American Mathematical Society 1976

2. Federer, H. : Geometric measure theory. Berlin, Heidelberg, New York: Springer 1969

3. Leray, J.: Acta Math. 63, 193-248 (1934) 
4. Mandelbrot, B.: Intermittent turbulence and fractal dimension kurtosis and the spectral exponent $5 / 3+B$. In: Turbulence and Navier-Stokes equation. Lecture Notes in Mathematics, Vol. 565. Berlin, Heidelberg, New York: Springer 1976

5. Scheffer, V.: Hausdorff measure and the Navier-Stokes equations. Commun. Math. Phys. 55, 97-112 (1977)

6. Scheffer, V.: The Navier-Stokes equations in space dimension four. Commun. Math. Phys. 61, 41-68 (1978)

7. Scheffer, V.: Partial regularity of solutions to the Navier-Stokes equations. Pacific J. Math. 66, 535$552(1976)$

8. Stein, E.M.: Singular integrals and differentiability properties of functions. Princeton: Princeton University Press 1970

9. Stein, E.M., Weiss, G.L.: Introduction to fourier analysis on euclidean spaces. Princeton: Princeton University Press 1971

Communicated by J. Glimm

Received September 9, 1979 